\title{
CONFRONTING COLONISATION: CONTEMPORARY CANADIAN AND AUSTRALIAN PICTURE BOOKS ABOUT INDIGENOUS PEOPLES
}

\author{
By
}

Katrina de Liberato, Honours Bachelor of Arts, University of Toronto, 2017

\author{
A Major Research Paper \\ presented to Ryerson University \\ in partial fulfillment of the \\ requirements for the degree of \\ Master of Arts \\ in the English MA Program \\ in Literatures of Modernity
}

Toronto, Ontario, Canada, 2019

CKatrina de Liberato 2019 


\section{AUTHOR'S DECLARATION FOR ELECTRONIC SUBMISSION OF A MAJOR RESEARCH PAPER}

I hereby declare that I am the sole author of this MRP. This is a true copy of the MRP, including any required final revisions.

I authorize Ryerson University to lend this MRP to other institutions or individuals for the purpose of scholarly research. I further authorize Ryerson University to reproduce this MRP by photocopying or by other means, in total or in part, at the request of other institutions or individuals for the purpose of scholarly research.

I understand that my MRP may be made electronically available to the public. 


\section{CONTENTS}

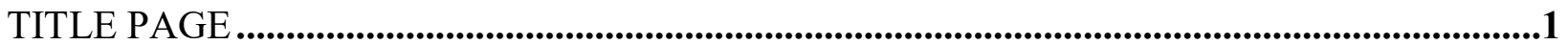

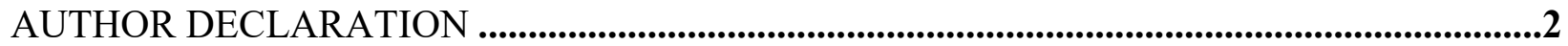

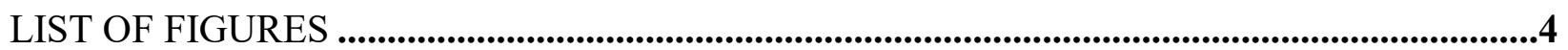

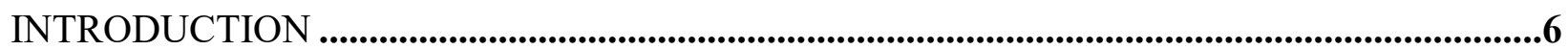

CANADIAN PICTURE BOOKS .........................................................................................................17

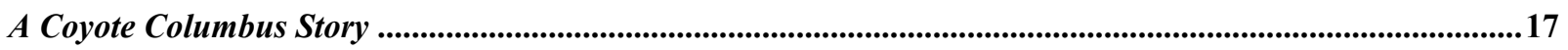

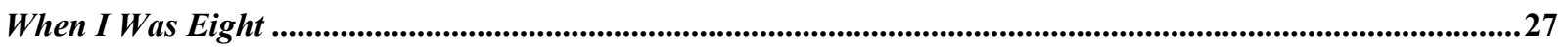

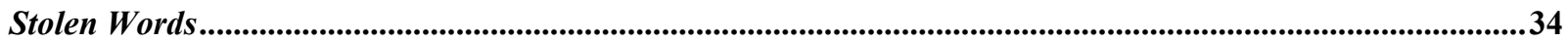

AUSTRALIAN PICTURE BOOKS...........................................................................................41

The Rabbits .........................................................................................................................................................................

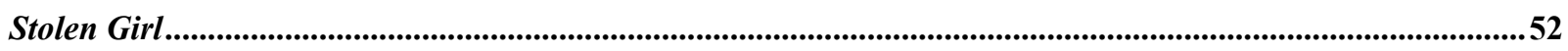

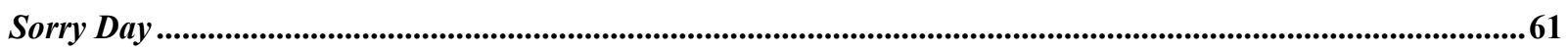

CONCLUSION ....................................................................................................................................68

WORKS CITED ..............................................................................................................................71 


\section{LIST OF FIGURES}

Figure $1 \quad$ A Coyote Columbus Story, text by Thomas King, illus. Willian Kent Monkman 20

Figure 2 A Coyote Columbus Story, text by Thomas King, illus. Willian Kent Monkman 21

Figure 3 A Coyote Columbus Story, text by Thomas King, illus. Willian Kent Monkman 25

Figure 4 A Coyote Columbus Story, text by Thomas King, illus. Willian Kent Monkman 26

Figure 5 When I Was Eight, text by Christy Jordan-Fenton and Margaret Pokiak-Fenton, illus. Gabrielle Grimard

Figure 6 When I Was Eight, text by Christy Jordan-Fenton and Margaret Pokiak-Fenton, illus. Gabrielle Grimard

Figure 7 When I Was Eight, text by Christy Jordan-Fenton and Margaret Pokiak-Fenton, illus. Gabrielle Grimard

Figure 8 Stolen Words, text by Melanie Florence, illus. Gabrielle Grimard

Figure 9 Stolen Words, text by Melanie Florence, illus. Gabrielle Grimard

Figure $10 \quad$ Stolen Words, text by Melanie Florence, illus. Gabrielle Grimard

Figure 11 The Rabbits, text by John Marsden, illus. Shaun Tan

Figure 12 The Rabbits, text by John Marsden, illus. Shaun Tan

Figure 13 The Rabbits, text by John Marsden, illus. Shaun Tan

Figure 14 The Rabbits, text by John Marsden, illus. Shaun Tan

Figure 15 The Rabbits, text by John Marsden, illus. Shaun Tan 
Figure 17 Stolen Girl, text by Trina Saffioti, illus. Norma MacDonald 55

Figure $18 \quad$ Stolen Girl, text by Trina Saffioti, illus. Norma MacDonald 57

Figure $19 \quad$ Stolen Girl, text by Trina Saffioti, illus. Norma MacDonald 59

Figure $20 \quad$ Stolen Girl, text by Trina Saffioti, illus. Norma MacDonald 60

Figure $21 \quad$ Sorry Day, text by Coral Vass, illus. Dub Leffler $\quad 63$

Figure $22 \quad$ Sorry Day, text by Coral Vass, illus. Dub Leffler 65

Figure $23 \quad$ Sorry Day, text by Coral Vass, illus. Dub Leffler 66

Figure $24 \quad$ Sorry Day, text by Coral Vass, illus. Dub Leffler $\quad 68$ 


\section{INTRODUCTION}

This paper will examine how Canadian and Australian picture books about Indigenous peoples have evolved over the past three decades into texts that imagine the survival of Indigenous languages and land despite colonisation. Drawing on a sample of six contemporary picture books about Indigenous peoples in present-day Canada and Australia, I will explore how these works challenge representations of Indigenous peoples as the Other through complimentary textual and visual techniques that instead Other colonists (Nodelman 29). By positioning European colonisers as foreign invaders who fail in their attempts to erase rather than understand vibrant Indigenous cultures, these texts enable Indigenous communities to symbolically reclaim the land, family, language, and identity taken by colonial forces. Contemporary Canadian and Australian picture books about the European colonisation of Indigenous peoples assert the value of Indigeneity by mobilising a juxtaposition of Indigenous versus non-Indigenous through contrasting shapes and colours that enhance textual differences between colonised and coloniser. While Canadian texts highlight the healing capabilities of Indigenous languages, Australian texts emphasise how symbiotic relationships with the land empower Indigenous peoples, reflecting geographical variations between Indigenous histories in each country that ultimately encourage diverse representations of Indigeneity.

These works so effectively portray Indigenous cultures thriving separate from colonial influence because the picture-book medium allows for a more emphatic distinction between Aboriginals ${ }^{1}$ and colonists through synergistic image-text relations than could be achieved

\footnotetext{
${ }^{1}$ While the term "Aboriginal" is in decline in Canada, it remains the preferred term in Australia. Though "Indigenous peoples" and "Aboriginals" appear interchangeably in the Introduction and Conclusion of this paper, I will use only "Indigenous peoples" within the Canadian Picture Books section and only "Aboriginals" within the Australian Picture Books section to reflect cultural preferences ("Terminology," "Preferences in Terminology when Referring to Aboriginal and/or Torres Strait Islander Peoples”).
} 
through text alone. I employ Lawrence R. Sipe's term "synergistic" to describe the "complicated and subtle" relationship between the "verbal and the visual texts" in picture books because it encapsulates how the works selected for this study convey a literary and visual Indigenous, nonIndigenous juxtaposition to celebrate the unique values of Indigenous cultures (97). Each text examined here exhibits an "additive" relationship in which flowing, colourful illustrations that evoke a harmonious connection between Aboriginals and nature oppose abrasive, monotone depictions of the colonists who threaten Indigenous land and identities to enhance narratives about colonial attempts to destroy Indigeneity (Wu 1416). By more exactly representing the appearance of the "signified" word through images — in this context, illustrations that denote Indigenous cultural vibrancy—picture books attract children to reflections of both "their immediate world and unknown worlds" (Graham 7). Doris Wolf and Paul De Pasquale suggest that picture books about Aboriginals, like those analysed in this paper, offer Indigenous children and communities "positive affirmation of their cultures and identities" through powerful synergistic verbal and visual representations of thriving Indigeneity despite colonisation (88). These texts employ both word and image to emphasise the value of surviving differences between Indigenous and European cultures and ultimately "challenge the dominance of white, middle-class characters and settings" in Canadian and Australian children's literature (89).

These contemporary texts respond to postcolonial theory by highlighting how the cultural differences between Indigenous and European populations typically employed by settlers to assert their superiority over Aboriginals actually celebrate Indigeneity. Because "dominant" European cultures "regard their own traditions, values, and practices as universal," literature about Aboriginals must find "strategies which enable recognition of what is specifically local and regional" to affirm the value of cultural variations that persist despite colonial attempts to 
educate non-Europeans "into being more like Europeans" (Stephens, Watson, and Parker 40, Nodelman 33). The picture books selected for this study achieve this objective by replacing derogatory representations of "Native-American presence in the mainstream culture defined and shaped by Anglo-American needs and concerns" with soft, colourful "realist depictions of contemporary indigenous American life" that not only humanise Aboriginals but also celebrate Indigeneity (Rivkin and Ryan 1100, 1103). According to Edward Said—whose research on nineteenth-century European discursive practices in the Middle- and Near-East is often applied to Indigenous children's literature by scholars like Perry Nodelman-Europeans took comfort in the differences between settler and colonised populations because these disparities supposedly affirmed European supremacy (39). The picture books examined here transform these cultural variations from an incentive for settlers to force "Western paternalist assistance" on Aboriginals so they better resemble Europeans into a source of pride across Indigenous cultures by positively representing Indigeneity (Rivkin and Ryan 1100). Through vibrant images that emphasise the inherent beauty of everyday Indigenous life — which remains distinct from European practices even after colonisation - these texts challenge colonial ideologies that position Aboriginals as an inferior Other.

After introducing the picture books selected for analysis in this paper, I will present a brief history of how colonisation impacted Indigenous peoples in present-day Canada and Australia respectively, focusing on the losses suffered by Indigenous peoples in each country following the arrival of colonial forces. This section of the paper will dedicate special attention to the experiences of Indigenous children who lived in government-mandated institutions, as four of the six texts I examine feature Indigenous protagonists who attend residential schools, children's homes, or missions. I will then outline publishing trends for Indigenous picture books 
to orient my paper within this evolving field and convey how the contemporary texts examined here differ from earlier postcolonial picture books before proceeding with an analysis of my selected Canadian texts. My examination of these works will progress chronologically from first contact between colonising forces and Indigenous populations in A Coyote Columbus Story (1992), proceeding to residential-school experiences in When I Was Eight (2013), and concluding with the lasting impact of colonisation in Stolen Words (2017). I will then examine the Australian texts in the same way, beginning with The Rabbits (1998), proceeding to Stolen Girl (2011), and concluding with Sorry Day (2018). This investigation aims to unpack how textual and visual opposition between the Indigenous and non-Indigenous in these texts uniquely affirms the persistence of Indigenous cultures in Canada and Australia despite colonial attempts to erase it.

The artistic contributions of Indigenous authors and illustrators in five of the six picture books analysed in this paper reflect how these texts work to authentically convey the ways Indigenous cultures thrive in postcolonial societies. Both the author and illustrator of $A$ Coyote Columbus Story are Indigenous. The text's author, Thomas King, is Cherokee and one of Canada's preeminent Indigenous public intellectuals (“Thomas King”). Its illustrator, William Kent Monkman, is a renowned Swampy Cree artist best known for his provocative investigation into the complexities of historic and contemporary Indigenous experiences through themes of colonisation, sexuality, loss, and resilience ("Biography”). My second Canadian text, When I Was Eight, is co-authored by Christy Jordan-Fenton and Margaret Pokiak-Fenton and illustrated by Gabrielle Grimard. While Jordan-Fenton and Grimard both identify as non-Indigenous, Pokiak-Fenton, whose childhood residential-school experiences inspired When I Was Eight, is Inuit, Inuvialuit, and Mackenzie Inuit. Stolen Words, my third Canadian text, is also illustrated 
by Grimard but authored by Melanie Florence, who identifies as Cree. I identify as a settler scholar of German-Canadian heritage with research interests in Indigenous literature and children's literature. This project, therefore, represents an exciting intersection between these disciplines. While colonisation itself grows increasingly distant as these picture books advance chronologically from A Coyote Columbus Story to Stolen Words, each text conveys how Indigeneity persists despite the enduring impact of oppressive colonial experiences through complimentary textual and visual techniques that establish an Indigenous, non-Indigenous juxtaposition to express the value of Indigenous cultures.

The Australian picture books selected for this study differ from my Canadian texts because unlike Stolen Girl and Sorry Day, The Rabbits concludes with Indigenous characters failing to reclaim their land, family, language, or identity after colonisation. Though both the author and illustrator of The Rabbits are non-Indigenous Australians-John Marsden is Caucasian while Shaun Tan is Chinese/Malay and Irish/English—much of Tan's other work, such as Tales from Outer Suburbia (2008) and The Lost Thing (2000), focuses on "displacement and troubled belonging," reflecting his own experiences as a biracial and bicultural child growing up in a predominantly white community (“Shaun Tan: Straight Talking Dreamer”). I include The Rabbits in my sample of picture books because I believe this text aims to honestly and respectfully represent Australian colonisation to young audiences and, therefore, deserves consideration alongside the remaining Indigenous stories examined here. The Rabbits additionally achieved great popularity and acclaim in Australia, winning the Children's Book Council's Picture Book of the Year Award. My second Australian text, Stolen Girl, is published by Magabala Books, an Australian press dedicated to the dissemination of Indigenous literature. Author Trina Saffioti identifies as a member of the Gugu Yulangi people of far north Queensland 
while illustrator Norma MacDonald is of the Yamitji people of the Gascoyne region and the Nyungar people of the south-west of Western Australia. Sorry Day, published by the National Library of Australia, is written by Australia's Coral Vass and illustrated by Dub Leffler, a member of the Bigambul people of south-west Queensland. Though an important picture book about the European colonisation of Aboriginals, The Rabbits portrays its Indigenous characters as helpless victims against colonists while Stolen Girl and Sorry Day feature protagonists who embrace their Indigeneity to thrive in postcolonial Australia, a discrepancy I will address further in my focused analysis of The Rabbits.

The European colonisation of Canada resulted in immeasurable death and displacement amongst its Indigenous peoples over the course of nearly five hundred years. Travellers from Spain, Portugal, France, and England began embarking on seasonal expeditions to Canada's east coast in the early sixteenth century to collect "terra firma, fresh water, and sex, along with fish, fur, and captives to take back home" (Conrad 27, 35). Despite their "episodic and seasonal" presence in North America, Europeans introduced devastating foreign diseases to Indigenous peoples that decimated significant but unrecorded portions of their populations (See). Decades of research suggests that smallpox alone killed fifty to seventy-five percent of Canada's Indigenous populations (Conrad 27). Though foreign voyageurs threatened the health of Indigenous peoples in North America, most continued voluntarily interacting with Europeans, especially fur traders (Creighton 16). As fur trade with Indigenous peoples developed into an "increasingly lucrative enterprise" over the sixteenth century, European monarchs incentivised their nobility to settle in Canada, leading to the rapid expansion of European communities into Indigenous territories and forcing Indigenous populations to migrate from their native territories (Conrad 32, Buckner 50). Though colonial infiltration of Indigenous land eventually compelled tribes like the Ojibwa, 
Ottawa, and Nipissing to retaliate against the Confederacy in battle, these confrontations-won predominantly by colonists - only further decimated Indigenous populations (Conrad 49). French and British settlers additionally worked to convert Indigenous peoples to their respective brands of Christianity, dividing and, therefore, weakening any remaining Indigenous communities against colonisers (See, Conrad 35). The European colonisation of Canada so severely decimated Indigenous populations across the country that Phillip Buckner describes their continued fight against colonists in the early nineteenth century as a "doomed resistance to the encroachment of settlement" (50).

While the European colonisation of Australia began nearly two centuries later than in Canada, Australia's gruesome history of the disease, murder, and displacement inflicted on Aboriginals by colonists mirrors Canada's. Though thermoluminescence dating proves that Indigenous bands settled in Australia approximately 60,000 years ago, Great Britain claimed Australia as a colony shortly after Captain James Cook discovered the country's east coast in 1770 (West 16, Konishi and Nugent 55-56). In 1788, Arthur Phillip sailed a ship filled with petty thieves to Botany Bay to reduce convict populations in England and begin settling Australia (Clarke 23). This humble group of colonists famously known as the First Fleet multiplied exponentially following the wool rush of the early 1800's and the 1850's gold rush, resulting in an outbreak of smallpox that killed nearly fifty percent of all Aboriginals in Australia (West 49, 58, Clarke 26). Thousands more of Australia's surviving Indigenous populations died in violent colonial attacks, including the 1824 Bathurst War, the 1825 Black War, and the 1838 Myall Creek Massacre (West 47-48, 52). By 1850, settlers had established over five hundred industrial companies across Australia's eastern coast, forcing Aboriginals out of their native territories and limiting cultural and linguistic variations across tribes (West 57, Konishi and 
Nugent 59). Because colonisation so aggressively devastated Indigenous populations throughout Australia, Aboriginals often commemorate Australia Day, celebrated on 26 January, as Invasion Day or Survival Day "to denote the beginning of the disease, violence, and invasive government policies that destroyed life as they knew it" (West 42).

While specific religious and educational practices varied across schools in both Canada and Australia, the purpose and structure of colonial institutions for Indigenous children remained similar. According to Antonio Buti, the governments established by European colonisers in both countries founded these institutions to assimilate Canadian or Australian Indigenous populations into European socio-economic-political systems, using Christianity as the primary tool for transforming Aboriginals across the colonies into reputable Europeans ("The Removal of Aboriginal Children: Canada and Australia Compared"). This systematic removal of traditional cultural, religious, and linguistic practices from Indigenous children in Canada began in 1880 when the first residential school was established with the express purpose of eliminating Canada's "Indian Problem" (Matheson, Bombay, Dixon, and Anisman 3). An 1884 amendment to the 1876 Indian Act instated government-mandated education for all Indigenous children, enabling government officials to forcibly remove Indigenous children from their homes and relocate them to residential schools (Matheson et. al 3). By 1920, the Canadian federal government required that all Indigenous children attend residential school for a minimum of ten months each year (Bombay, Matheson, and Anisman 322). The mandatory government education of Aboriginal children began later in Australia than in Canada, with the Aboriginal Protection and Restriction of the Sale of Opium Act of 1897 permitting the removal of Aboriginal children from their families (Walters 134). By 1937, government officials gathered at the Canberra Conference of the Commonwealth and State Aboriginal Affairs Ministers passed a 
policy supporting the complete absorption of Aboriginals into the European population, effectively sanctioning the abolishment of Indigenous practices in Australia (Buti). When the last government institutions for Aboriginal youth closed in the 1990's in Canada and Australia alike, over 150000 Indigenous children in Canada had attended residential school and over 100000 Aboriginal children in Australia had been stolen from their families (Bombay et. al. 322).

Although settlers appropriated Indigenous stories throughout most of the twentieth century—-hampering the dissemination of accurate information about Aboriginals throughout Canada and Australia alike — the genre of Indigenous literature, including picture books, has grown tremendously over the past four decades (Edwards and Saltman 199-200). According to Gail Edwards and Judith Saltman, the content of Indigenous picture books has increasingly shifted from "romanticized and sentimentalized narratives of a dying culture" to more intimate stories about "contemporary Aboriginal families living in the modern world" since the 1980's (201). Clare Bradford suggests that the recent institution and development of Indigenous publishers, such as Pemmican and Theytus in Canada and Magabala Books and IAD (Institute of Aboriginal Development) in Australia, reflects the popularity of children's literature in particular as an outlet for individual and cultural expression amongst Indigenous peoples (4). Because picture books are the "most common form of children's books [produced] by Aboriginal authors," hundreds of new titles have been published in each country over the past forty years (Wolf and De Pasquale 87, 89). These texts typically feature "intergenerational Aboriginal narratives, in which the elders pass on their traditions and teach the younger generations about the "power of nature and meaning of life"' (Edwards and Saltman 206). My own perusal of over fifty Indigenous picture books published since 1990 confirmed this observation. In most of the texts I encountered, such as Nokum is My Teacher (2007), Lessons from Mother Earth (2002), 
and Fair Skin Black Fella (2010), tribal elders inform Indigenous children about their cultural heritage, so they can embrace their Indigeneity in a contemporary setting. While such narrative trends have emerged in recent years, countless other Indigenous picture books, like those examined in this paper, explore diverse subjects that contribute to a better understanding of Indigenous histories, spiritual beliefs, and cultural practices amongst Indigenous and nonIndigenous readers alike.

The texts selected for this study simultaneously challenge and perpetuate thematic and stylistic trends in Indigenous picture book publishing over the past three decades. Notably, unlike most fictional picture books by Indigenous authors, these works confront rather than avoid "the historical past, especially the nineteenth century" by directly addressing colonisation and its repercussions (Wolf and De Pasquale 90). In my search to collect a sample of fictional contemporary Canadian and Australian picture books about the European colonisation of Indigenous peoples, I found only a handful of texts that dealt explicitly with these issues. Bradford suggests that most Canadian and Australian picture books written by or about Indigenous peoples "enact a repression of memory concerning colonisation, a manifestation of what Freud and Lacan describe as Verdrängung, the process of censoring and so forgetting a painful past redolent with violence and conflict" (3). In other words, the emotional and physical distress associated with reflecting on traumatic colonial events often prevents Aboriginals from telling stories about colonisation, resulting in an overabundance of settler narratives that threaten to eclipse and even erase Indigenous perspectives on these experiences. According to Wolf and De Pasquale, Indigenous picture books that indirectly address colonisation also risk perpetuating colonial stereotypes about Aboriginals by unintentionally caricaturing Indigenous peoples and lifestyles (102). Consequently, this prevalent genre of subversive protest literature can actually 
degrade rather than empower Indigenous voices. Because the picture books analysed in this paper are atypically direct in their treatment of colonisation, they embody a unique and important category of Indigenous-picture-book publishing intended to disseminate explicitly positive representations of Aboriginals.

However, while these stories are more clearly situated in relation to colonial events than most children's literature about Aboriginals, they draw on the same themes using similar artistic styles. For example, Lorraine Beveridge and Julie Hinde McLeod identify "the extreme importance Aboriginal people place on connecting with their land or country" as a prominent theme in Australian Indigenous picture books, one which predominates in the stories analysed here (191). In fact, Canadian picture books, both Indigenous and non-Indigenous, continue to present the wilderness as "an edenic space for childhood" though "the majority of Canadian children today live on the southern borderland in urban, ethnoculturally diverse communities" (Edwards and Saltman 195). Wolf and De Pasquale argue that these texts persistently "foreground the idyllic" when depicting Indigenous landscapes to "highlight the interconnectedness of land and people common to Aboriginal worldviews," helping readers appreciate the environmental practices distinctive of Indigenous cultures $(92,99)$. While many Indigenous picture books present only lush earth untouched by colonisation, the texts I examine here contrast bountiful Indigenous landscapes with barren colonial industry to emphasise the persistence of Indigeneity despite colonisation rather than exclusively the richness of Aboriginal life before it (92). Though the Canadian and Australian texts selected for this paper employ common Indigenous-picture-book techniques for expressing Aboriginal values, they more actively protest colonisation by addressing how colonial forces threaten Indigenous environments. 


\section{CANADIAN PICTURE BOOKS}

\section{A Coyote Columbus Story}

Illustrated in psychedelic hues, A Coyote Columbus Story delivers a third-person account of Coyote the trickster, an Indigenous mythical figure responsible for creating the world within this text. Despite Coyote's charge to "fix up this world," she spends most of her days recruiting anyone with whom she can play ball (King and Monkman). When all the animals and Indigenous peoples Coyote creates refuse to play with a trickster who constantly bends the rules of ball in her favour, Coyote creates new humans. But instead of ball-players, Christopher Columbus and his crew arrive on Coyote's Canadian shores. Determined to bring Indian riches to Spain, Columbus convinces his crew that the Indigenous peoples are actually "Indians" and ships them off to Europe. After Columbus leaves to sell the Indigenous peoples he successfully collected, the animals and humans who managed to evade him demand that Coyote rectify her mistake. Though Coyote tries to "take Christopher Columbus back," she only summons more colonisers (King and Monkman). As Jacques Cartier and his crew reach Canada in search of India, all the remaining animals and Indigenous peoples flee to Penticton. The story ends with Coyote attempting to interest the French colonisers in a game of ball, simultaneously gesturing towards the ensuing French settlement of Canada while leaving Coyote's fate ambiguous.

King and Monkman sensationalise Canadian colonial history to attract a broader demographic of readers by drawing on the fame of explorers Christopher Columbus and Jacques Cartier. Though A Coyote Columbus Story suggests that Columbus first landed in Canada while searching for India, his late-fifteenth-century voyages actually led him to the Caribbean (Conrad 30). With explorers like Columbus laying claim to non-Christian lands such as Asia and Central and South America for Spain or Portugal, France and England grew eager to secure their own 
conquests and began embarking on regular expeditions to Canada in the early sixteenth century (Cahill and Ouellet 75-76). The 1534 and 1535 expeditions of Jacques Cartier represent the first European voyages resulting in a successful claim of Canadian land (94). Though most of Cartier's crew succumbed to scurvy and Cartier's own widely-circulated documents prove his mistreatment of the Mi'kmaq and Iroquois peoples he encountered near the site of present-day Montreal, causing them to disappear from the St. Lawrence region, Cartier is credited with laying the foundations for French Canada (Conrad 31, 35). He appears at the end of $A$ Coyote Columbus Story, foreshadowing the imminent oppression European colonisers will inflict on the Indigenous peoples of Canada. The ways A Coyote Columbus Story misrepresents Canadian colonial history reflects how the text hyperbolises and homogenises colonisers by portraying them as flamboyant Europeans who behave dramatically.

King and Monkman contrast Indigenous and colonial appearances and cultural practices to highlight a juxtaposition between Indigenous and non-Indigenous temporalities, indicating that Indigenous cultures can thrive without colonial intervention. Both text and illustration in $A$ Coyote Columbus Story stress the silliness of colonisers' appearances to convey this opposition. When Coyote first spots Columbus and his crew, she describes them as "people in funny-looking clothes," which Monkman emphasises through his images of the colonisers' boisterous accessories, including fishnet stockings, high heels, and massive gold crosses on thick chain necklaces (King and Monkman). Additionally, Indigenous characters wear current, form-fitting clothing while colonisers don dated, angular fashions, highlighting a temporal distance between Indigenous peoples and colonists in this text that enforces their cultural differences (see fig. 1). Monkman also positions Indigenous characters near the bottom of his illustration with Coyote suspended overhead, gesturing towards her spiritual significance and suggesting a freeness that 
counters Indigenous peoples' rootedness in the earth both physically and culturally (Bang 78). While the historical period from which each coloniser's outfit emerges ranges from the sixteenth to the twentieth century, dated styles predominate throughout. Much of the crew wear capes, epaulets, or ruffs that locate them within the colonial era while others wear ties and page-boy hats distinctive of the early-twentieth century (see fig. 2). Monkman further emphasises the antiquity and imperfection of these styles through the clownlike patches that adorn every item of coloniser clothing. This opposition between late-twentieth-century Indigenous and dated nonIndigenous clothing alludes to the ways Indigenous and colonial temporalities differ. In his book Beyond Settler Time, Mark Rifkin explores how 'Native peoples' varied experiences of duration can remain nonidentical with respect to the dynamics of settler temporal formations, indicating ways of being-in-time that are not reducible to participation in a singular, given time - a unitary flow—-largely contoured by non-native patterns and priorities," meaning that Indigenous temporalities have their own "coherent yet changing" flow completely separate from settler time (3). Consequently, Indigenous understandings of their own cultural practices at a given time may not align with how settlers perceive those same behaviours. These disparate understandings of time are reflected in textual and visual differences between Indigenous and non-Indigenous clothing in A Coyote Columbus Story and help explain why Columbus denigrates Indigenous peoples as though they are subhuman though they exhibit more cunning and resourcefulness than colonisers throughout the text. By juxtaposing Indigenous and coloniser clothing through contrasting shapes, Monkman highlights temporal differences between Indigenous and nonIndigenous fashions that draw attention to the modernity of Indigenous styles relative to colonial 
historical garb, conveying the significance of divergent Indigenous and settler temporalities.

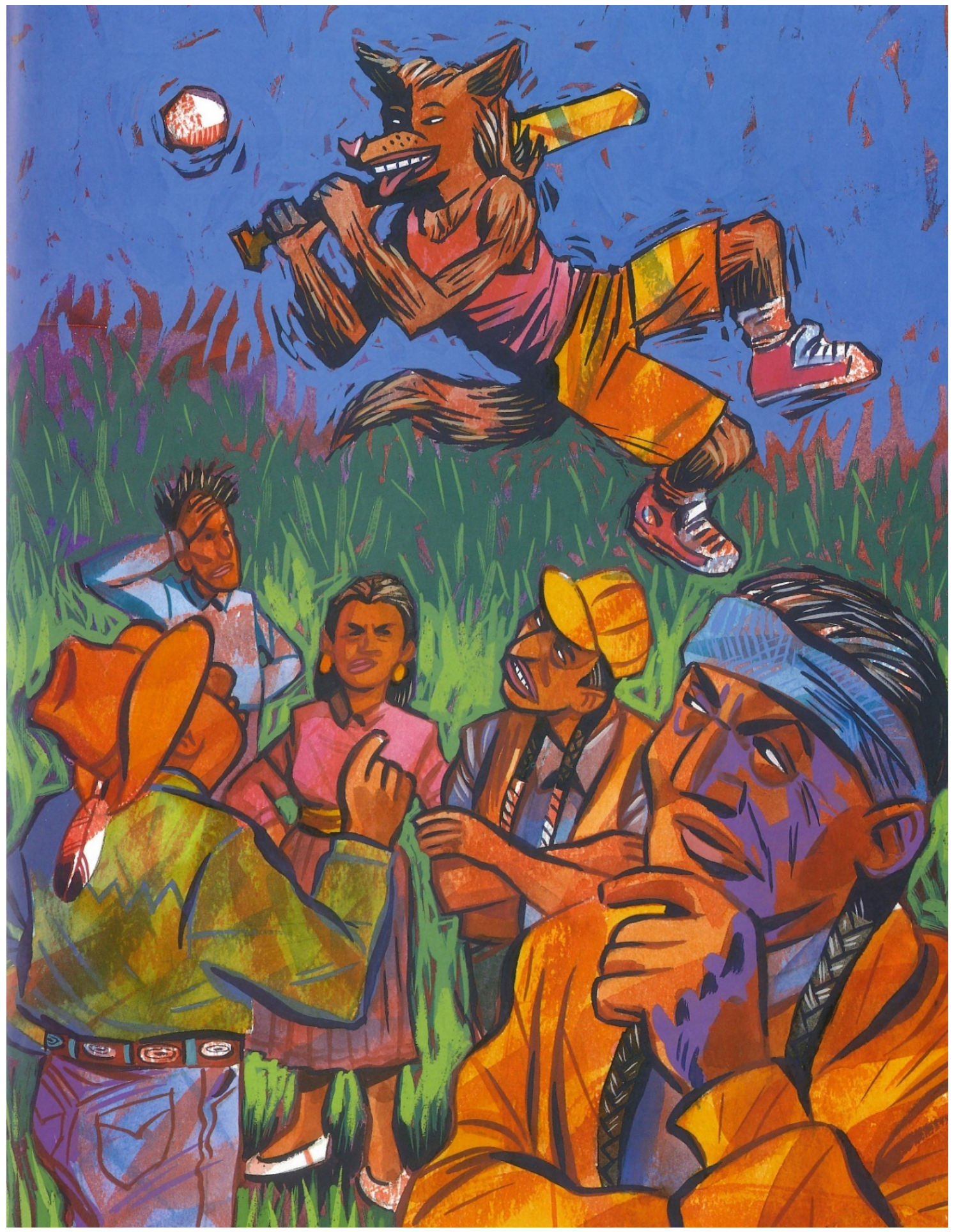

Fig. 1. Coyote suspended above a group of Indigenous characters with ball and bat: King, Thomas, and William Kent Monkman. A Coyote Columbus Story. House of Anansi Press, 1992. 


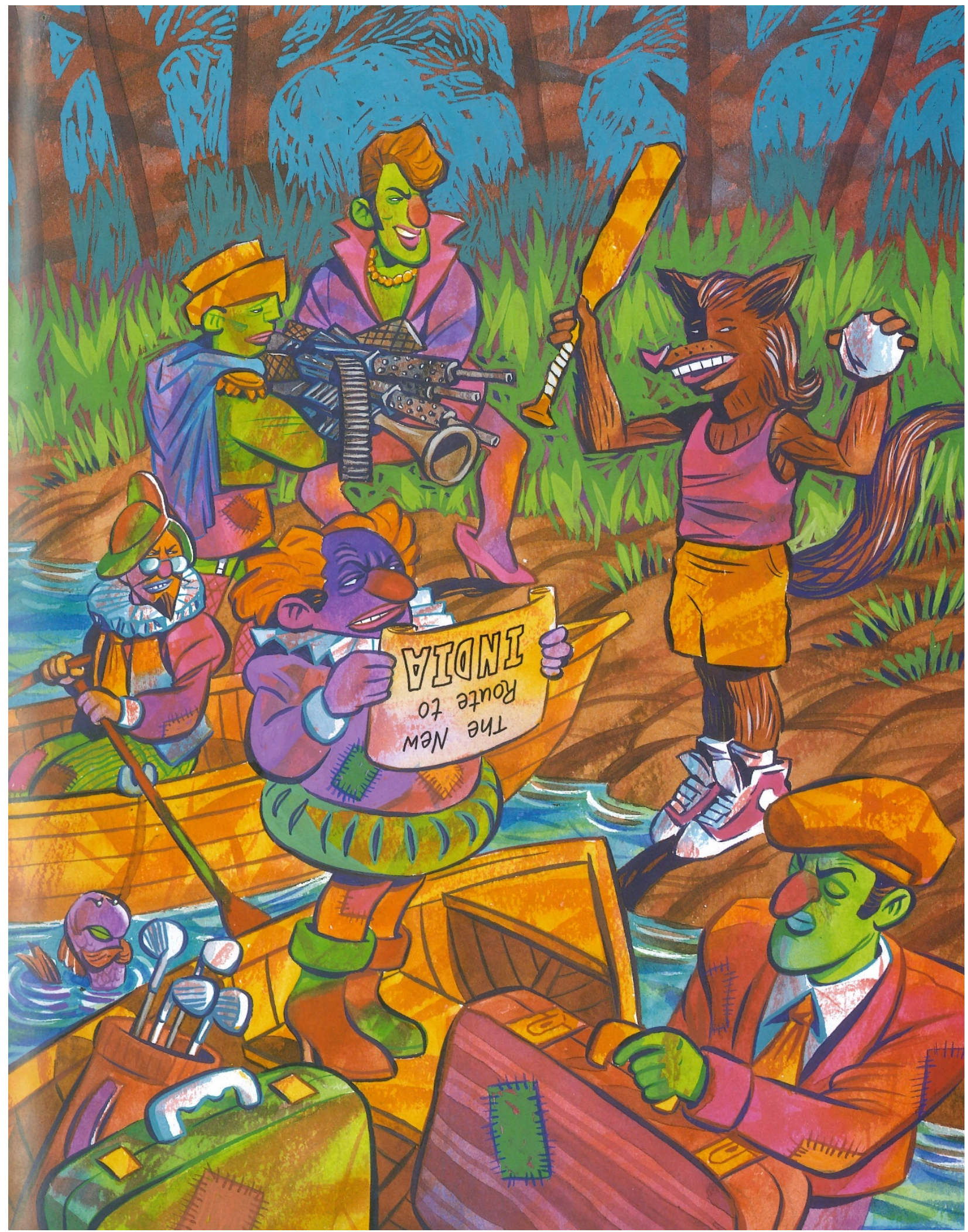

Fig. 2. Columbus holding an upside-down scroll labelled "The New Route to India" as he and his crew land on Canadian shores: King, Thomas, and William Kent Monkman. A Coyote Columbus Story. House of Anansi Press, 1992. 
Monkman's use of opposing shapes when depicting coloniser and Indigenous clothing enhances King's descriptions of Indigenous peoples engaging in modern activities that convey their sophistication as a people. Before Columbus and his crew arrive from Europe by wooden ship, King explains that the Indigenous peoples "go shopping. Some of them go sky diving. Some of them go to see big-time wrestling. Some of them go on a seven-day Caribbean cruise," suggesting that Indigenous technology is more advanced than that of European colonisers. Indigenous characters in this text are not only familiar with modern technology but also perfectly content with their lifestyles prior to colonial interference. King even notes, "Those human beings got better things to do than play ball with Coyote and those changing rules" to both assert that Indigenous characters reject Coyote's manipulation and foreshadow how they later recognise Columbus' plan to sell them in Spain as "a bad idea full of bad manners," and then disguise themselves as animals to evade him (King and Monkman). Additionally, Coyote's propensity to bend the rules of ball in her favour contributes to her unreliability, further complicating her already ambiguous role within the text. Monkman contrasts Indigenous cleverness and technology with brutish colonial weapons by depicting Columbus' crew with machine guns intended to help corral Indigenous peoples into boats bound for Spain. As some of the only modern technology employed by colonists throughout the text, these guns enforce how Columbus and his crew threaten Indigeneity. A Coyote Columbus Story ultimately suggests that Indigenous peoples enjoyed full lives before colonists subjected them to "civilising" European influences because Indigenous communities were already intellectually, technologically, and socially advanced (Buti). By combining historical eras within this text, King and Monkman emphasise a juxtaposition between Indigenous and non-Indigenous lifestyles to affirm the precolonial stability of Indigenous cultures. 
Monkman contrasts neutral Indigenous and neon coloniser skin and hair colours to further convey how positive Indigenous relationships with nature benefit the land and Indigenous peoples alike. While Monkman depicts Indigenous characters with brown skin and black hair, he illustrates Columbus and his crew with purple, green, blue, or orange skin; pink or red noses; and multicoloured lips that distinguish natural Indigenous appearances from hyperbolic colonial ones. Those members of Columbus' crew with hair sport varying shades of brown, but the Columbus character is depicted with wild bright red hair that likens him to a clown. This satirical comparison subversively contests Columbus' heroic status as the founder of modern America, particularly in the United States where Columbus Day is still celebrated as an annual national holiday. Monkman establishes a relationship between the colonisers' exaggerated skin and their aversion to wildlife through his illustration of animals avoiding, scorning, or attacking Columbus' crew as they invade natural spaces without considering how their actions impact the land (see fig. 3). Wolf and De Pasquale argue that colonists, like Columbus and his crew in $A$ Coyote Columbus Story, abuse Indigenous landscapes because they have yet "to learn about the fragility of the natural environment and the detrimental impact even...one small action can have" (101). Consequently, European colonisers often struggle to understand how Indigenous "connections to the land are lived as forms of bodily sensation, intimately part of the flow of temporal experience" and, therefore, remain separate from nature and Indigenous peoples alike (Rifkin 36). Through his depiction of Columbus' crew disrupting Indigenous landscapes, Monkman suggests that the colonists' unnatural skin symbolises their distance from nature and, by extension, the Indigenous peoples who protect it.

These intermingling old and new or natural and abstract ontological realms enable $A$ Coyote Columbus Story to confront dominant representations of Canada's colonial history by 
questioning their reliability. When King and Monkman depict colonisers wearing antiquated clothing alongside Indigenous peoples wearing contemporary clothing, they blur temporal boundaries, collapsing cultural hierarchies imposed by colonists that position European civilisations above Indigenous ones (Lyon 10). With little white space dividing the domineering shapes and colours that characterise colonial garb throughout the work, the senses quickly grow overwhelmed, generating an almost hallucinogenic quality that advances the text's exploration of flexible temporalities. This "collision of different worlds"-in addition to other distinctly postmodern-picture-book elements featured in A Coyote Columbus Story, such as a blurring between high and low culture through lyrical narrative regularly interrupted by repeated instances of improper subject-verb agreement like "they says," or a failure to offer closure through the text's indeterminate ending — work to "interrogate and problematize conventional representations of an historical past" by drawing "attention to history as a construction and question[ing] its ability to accurately represent the past" (Allan 11, 13, Lyon 10). Combining opposing language, temporalities, shapes, and colours throughout this text "destabilizes the ontological status of [its] central ontological world," making A Coyote Columbus Story fundamentally ambiguous (Allan 11). Though Coyote's story is firmly grounded within the contemporary Indigenous framework established in the picture book's opening pages, the text resists categorisation into a single ontological realm through its ambiguous portrayal of the role Coyote plays throughout and its conflicting representations of colonists and Indigenous peoples. By employing destabilising postmodern-picture-book techniques throughout $A$ Coyote Columbus Story, King and Monkman evoke an ontological ambivalence that encourages consideration about whether "we should...readily accept all that history presents" (13). 


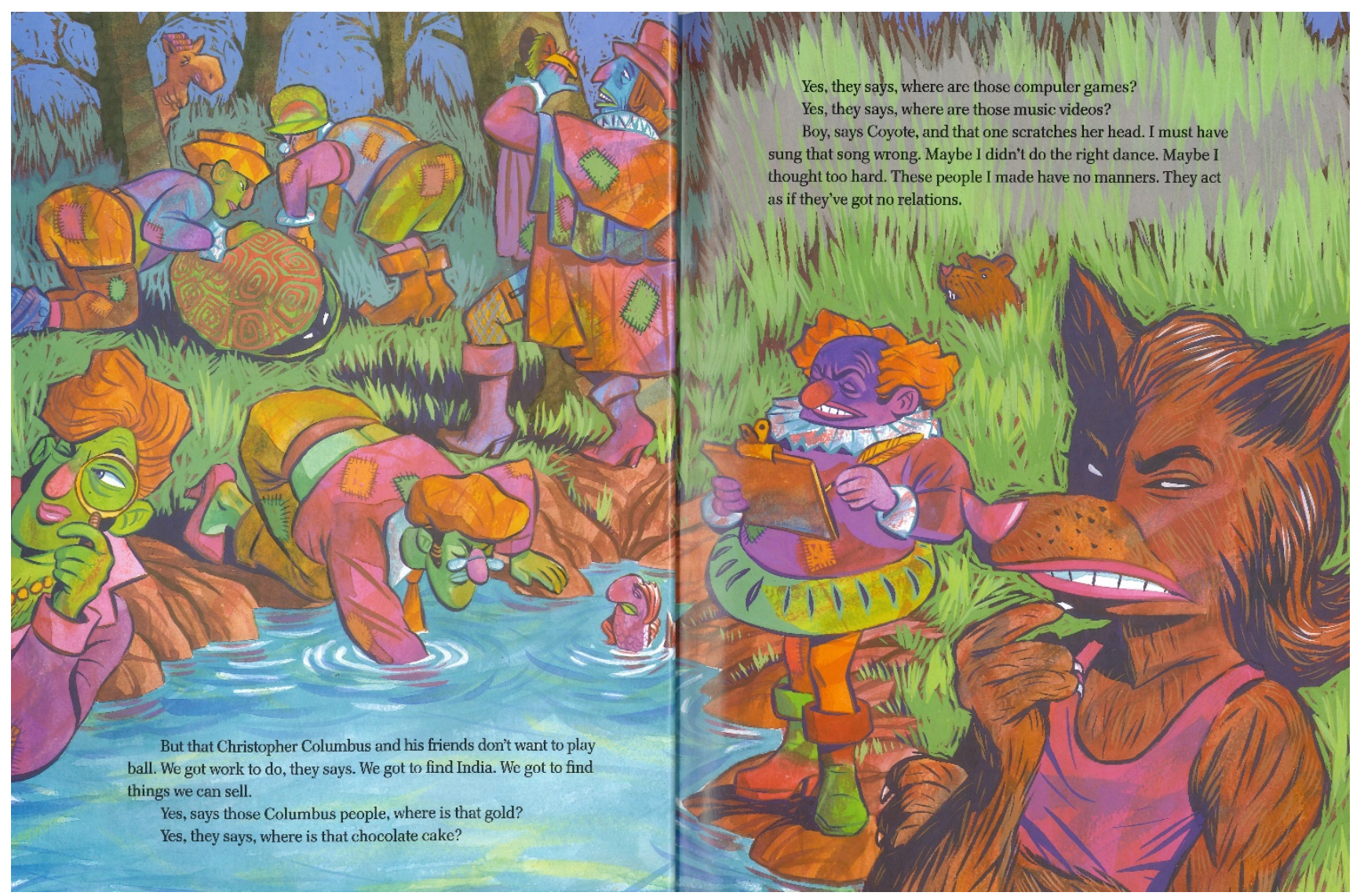

Fig. 3. Columbus and his crew searching for riches in Canada: King, Thomas, and William Kent Monkman. $A$ Coyote Columbus Story. House of Anansi Press, 1992.

King and Monkman affirm the value of nature in Indigenous cultures when Indigenous characters save themselves from being sold in Spain by impersonating animals to hide from colonisers. When Columbus commands his men to “[g]rab some more Indians," King's Indigenous characters "jump in the pond" and pretend to be beavers, turtles, and moose (King and Monkman). While their neutral skin colour and familiarity with the land enables these Indigenous characters to employ natural objects like sticks to masquerade as animals, Columbus' distance from nature prevents him from successfully distinguishing between Indigenous peoples camouflaged as animals and actual animals (see fig. 4). This scene additionally evokes colonial perceptions of Indigenous peoples as animalistic beings, further explaining Columbus' inability 
to identify the disguised Indigenous characters as humans (Moberg 47-48). Because Indigenous peoples understand that "all of nature is a garden that can be harvested, but only if it is respected," the land protects them from Columbus (Wolf and De Pasquale 92). By contrast, Columbus cannot recognise the value of nature and consequently misses his opportunity to partake in the prosperous fur trade largely responsible for initiating European settlement in Canada (Conrad 32). King alludes to Columbus' mistake when his crew lists the monetary value of different animals who "run and hide before Columbus and his friends change their minds" after Columbus degrades all wildlife, saying animals “aren’t worth poop” (King and Monkman). A Coyote Columbus Story opposes respectful Indigenous and destructive colonist relationships with nature to covey how the land offers reciprocal support to Indigenous peoples.

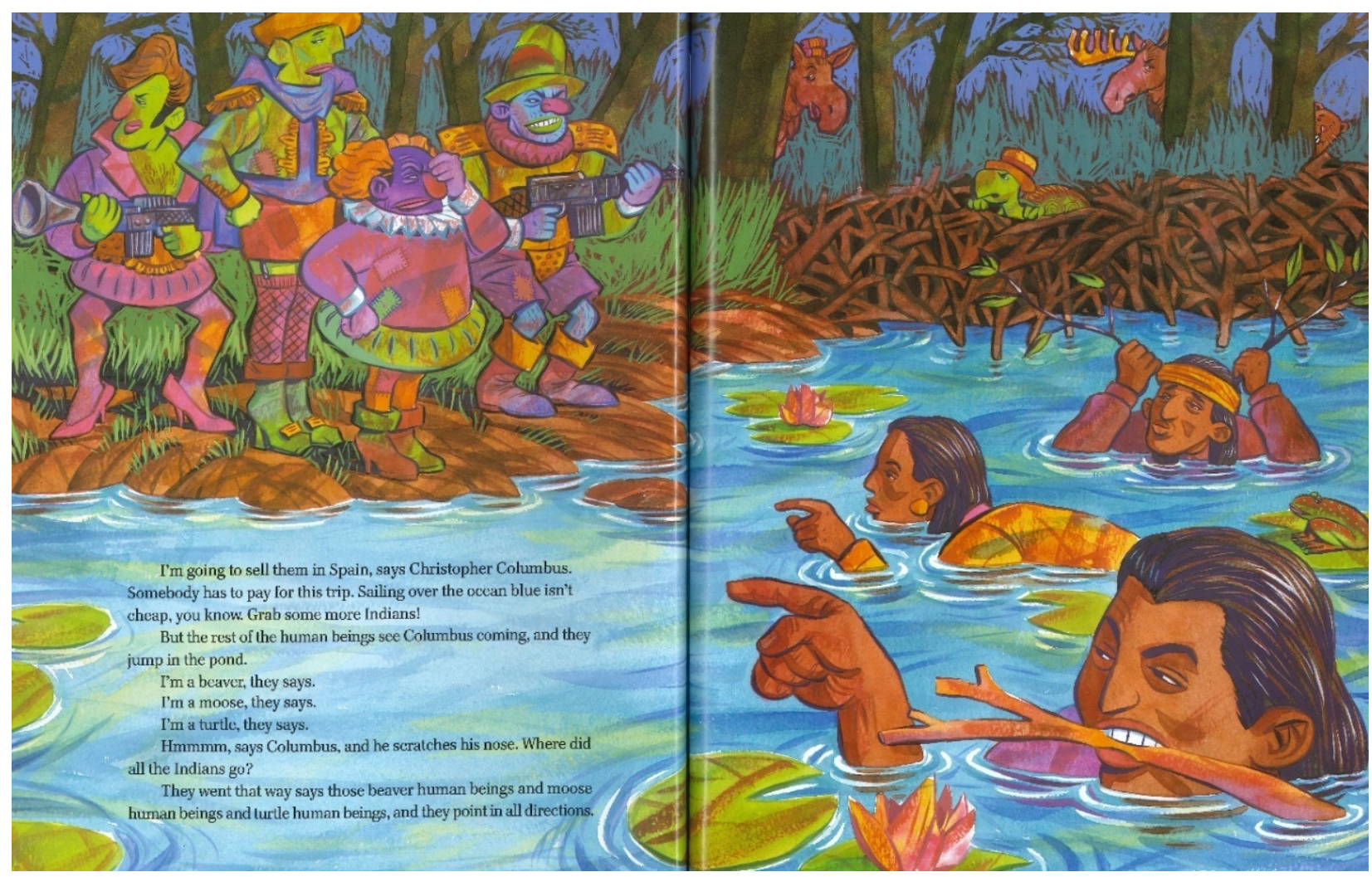

Fig. 4. Indigenous characters disguising themselves as animals to evade capture by Columbus and his crew: King, Thomas, and William Kent Monkman. A Coyote Columbus Story. House of Anansi Press, 1992. 


\section{When I Was Eight}

While A Coyote Columbus Story primarily addresses how early European colonisation impacted Canadian land and wildlife, When I Was Eight confronts the effects of residential schools on Indigenous identity. Told from the first-person narrative perspective of Margaret Pokiak-Fenton, When I Was Eight is a fictionalised account of her childhood residential-school memories. This intimate point-of-view helps reinforce not only the text's basis in PokiakFenton's lived experiences but also the need for children who attended residential schools to maintain a connection with their Indigenous origins to survive the abuse they endured there (Barnes and Josefowitz 68-69).

The memoir begins in Northern Canada where an eight-year-old Inuit girl called Olemaun, a name meaning "the stubborn stone that sharpens the half-moon ulu knife used by [Inuit] women," dreams of learning to read (Jordan-Fenton, Pokiak-Fenton, and Grimard). After months of begging, Olemaun's father reluctantly allows her to attend residential school. But when Olemaun arrives, she soon discovers that rather than teaching students to read, residentialschool nuns force the girls to perform grueling chores and unfamiliar religious rituals, addressing how Canadian government institutions for Indigenous children that claimed to civilise students through education actually dedicated little time to classroom learning (Bombay et. al. 322). One nun in particular resents Olemaun's enthusiasm for reading and stops at nothing to humiliate and frighten her. But Olemaun works hard until she can eventually read perfectly, besting the nasty nun once and for all.

In When I Was Eight, Grimard visually contrasts soft, colourful Indigenous faces and environments with angular, dark colonial ones to express a juxtaposition between Indigenous and non-Indigenous characters and settings that emphasises Olemaun's resilience against residential- 
school nuns who work to inhibit her learning. This text highlights how nuns threaten Olemaun's intellectual freedom through a scene in which a nun prevents Olemaun from reading and punishes her for expressing a desire to read. After Olemaun rushes through supper to read in her dormitory, a nun orders Olemaun to scrub pots "in a threatening tone," attempting to extinguish Olemaun's excitement for learning with painful physical labour (Jordan-Fenton, Pokiak-Fenton, and Grimard). This scene addresses the countless grueling and often dangerous chores religious officials typically responsible for operating residential schools forced upon Indigenous children (Buti). Many residential-school nuns, like the one represented in When I Was Eight, also administered inhumane emotional and physical punishment to children who failed to adequately perform their mandated duties; these included yelling, assigning of additional chores, hitting, and public humiliation (Buti). As Olemaun dutifully washes dishes, she reveals her stubbornness by muttering "I could be reading," provoking the nun to pin Olemaun "against the sink. Slowly a smile spread across her thin lips. 'Fetch me a cabbage from the basement,' she ordered" before locking Olemaun in the dark, further bullying Olemaun to destroy her determination to read (Jordan-Fenton, Pokiak-Fenton, and Grimard). These interactions convey a power imbalance between the nun — who enjoys employing her superior size and standing at the residential school to intimidate Olemaun into a position of servitude — and eight-year-old Olemaun. Grimard dramatizes this disparity between malicious colonial nun and resilient Indigenous child through her accompanying illustration of this scene.

Grimard's use of juxtaposing shapes when illustrating faces throughout When I Was Eight enhances Jordan-Fenton and Pokiak-Fenton's exploration of how Olemaun's Indigenous identity triumphs over colonial oppression. In her image of Olemaun and the nun's standoff, Grimard foregrounds the pinched, pointiness of the nun's countenance to emphasise a contrast 
between her angularity and Olemaun's softness. While the nun towers over Olemaun with squinted eyes, narrow face, and pointed chin, Olemaun stares defiantly up at the nun with a wide, round face and soft lips (see fig. 5). The sharp shapes Grimard employs to depict the nun's facial features, therefore, further convey her colonial threat to Olemaun's Indigeneity by exaggerating the power imbalance between them. But despite the nun's physical and authoritative control over Olemaun, the child stands with crossed arms and raised chin, enforcing her Indigenous namesake. This opposition is further expressed through the colours donned by each respective character. While the nun's black habit connotes negativity and repression, Olemaun's green dress connotes positivity and growth, reflecting how her stubbornness empowers Olemaun to oppose colonial rule. The nun's racist “deployment of power against groups perceived as inferior at both institutional and individual levels because of their skin colour" can interfere with Olemaun's ability to form positive self-identity, impeding the "development of affirmative feelings about" her racial or ethnic group (Barnes and Josefowitz 68). Consequently, Olemaun's sustained confidence in her capacity to learn reading despite colonial efforts to demoralise her becomes even more impressive. Grimard's visual contrast between angular colonial and round Indigenous faces helps assert a physical disparity between threatening residential-school nuns and powerless girl-students that reflects the destructive power imbalances embedded within the residentialschool system. By conveying Olemaun's fearlessness despite her obvious disadvantage against the imposing nun, this illustration enforces how Olemaun's seemingly unbreakable Indigenous spirit enables her to remain strong following confrontations with powerful colonists. 
de Liberato 30
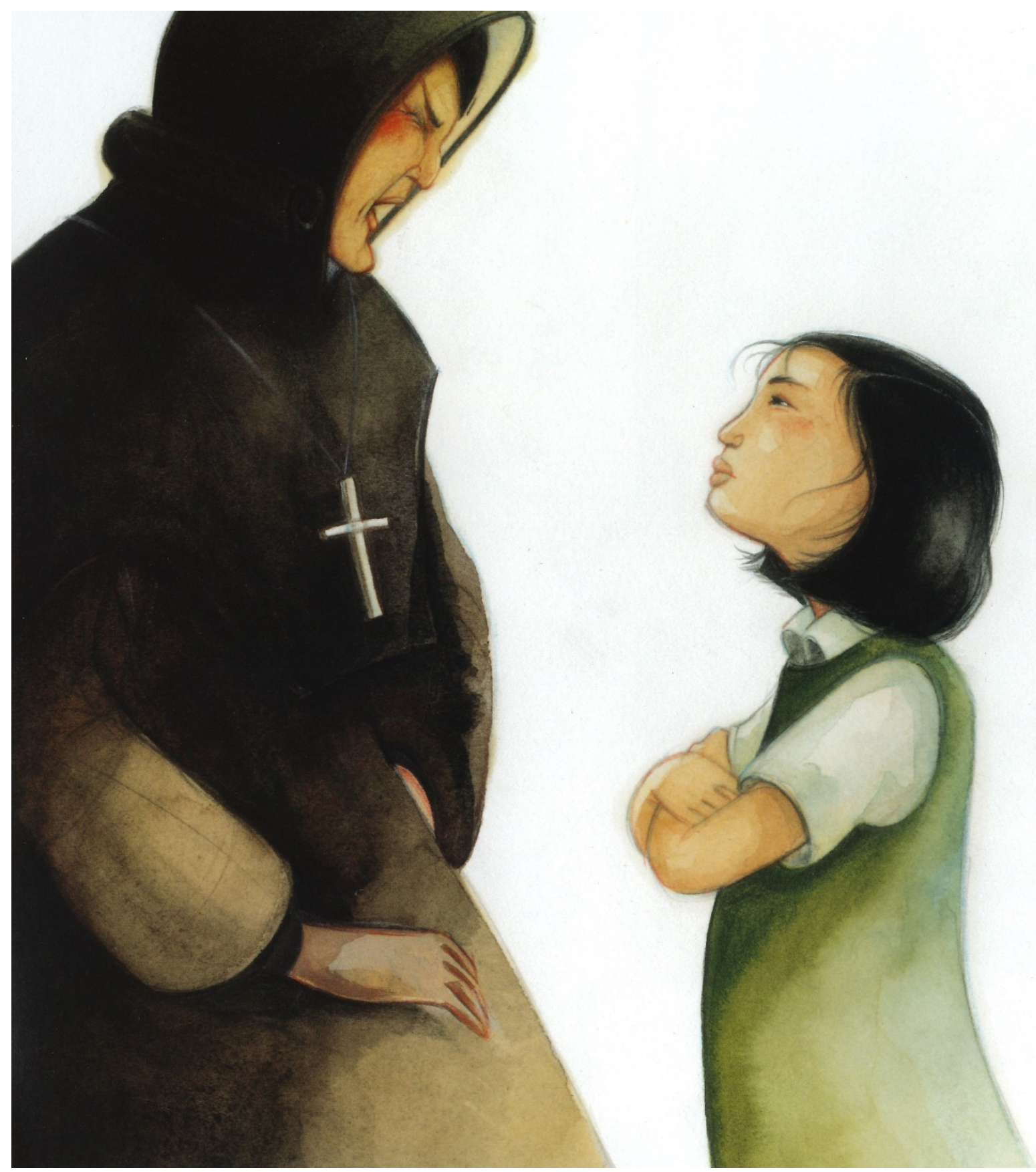

Fig. 5. A standoff between Olemaun and a residential-school nun: Jordan-Fenton, Christy, Margaret Pokiak-Fenton, and Gabrielle Grimard. When I Was Eight. Annick Press, 2013.

Juxtaposing images of Olemaun's soft and colourful home environment and the residential school's harsh, dark interior, further distinguish Olemaun's Indigenous identity from the oppressive colonial forces intended to destroy it. The plush furs, rounded igloo, and rich 
de Liberato 31

colours distinctive of Olemaun's Inuit home starkly oppose the black void spread over two pages with only an angular staircase descending into its depths that represents the residential school's basement (see fig. 6). Grimard contrasts black text that pushes down on Olemaun's head as if forcing her into the abyss with white text placed in the bottom corner of the illustration where only darkness awaits her, marrying text and image to stress how the nun works to eliminate Olemaun's hopefulness—-symbolised by the sliver of light shining in from the doorway—by locking her in the basement (Sipe 101-103). While Olemaun expresses confidence about her knowledge of Indigenous life in her home environment, as Olemaun ventures into the basement for the nun's cabbage, she thinks, "I'd heard stories of children who disappeared down in that dark cavern" (Jordan-Fenton, Pokiak-Fenton, Grimard). Olemaun's use of the word "disappeared" could dually reference the numerous children who died in residential schools or suggest that children lose their Indigenous identities in the foreboding basement (Barnes and Josefowitz 69). Rosemary Barnes and Nina Josefowitz explain that, like Olemaun, Indigenous children at residential schools were often "locked up in broom closets, basements, or even crawl spaces for long periods of time" (69). This psychological abuse "encourages the child to believe that he or she is worthless, flawed, unloved, unwanted, endangered, or of value only in meeting another's needs" and, therefore, contributes to the destruction of Indigenous identities (69). Olemaun proceeds to explain, "I descended each step deliberately, hiding my fear. My hands quickly found a cabbage in the shadows and I scurried up the stairs. But [the nun] slammed the door, shutting out all light" (Jordan-Fenton, Pokiak-Fenton, and Grimard). The shadows described and depicted in this scene convey how the nun attempts to stifle Olemaun's determination to read using the residential school's most menacing environment. By enhancing the text's distinction between Olemaun's nurturing home and the suffocating residential school 
using juxtaposing shapes and colours, Grimard emphasises how evil colonial environments threaten to disempower Olemaun.

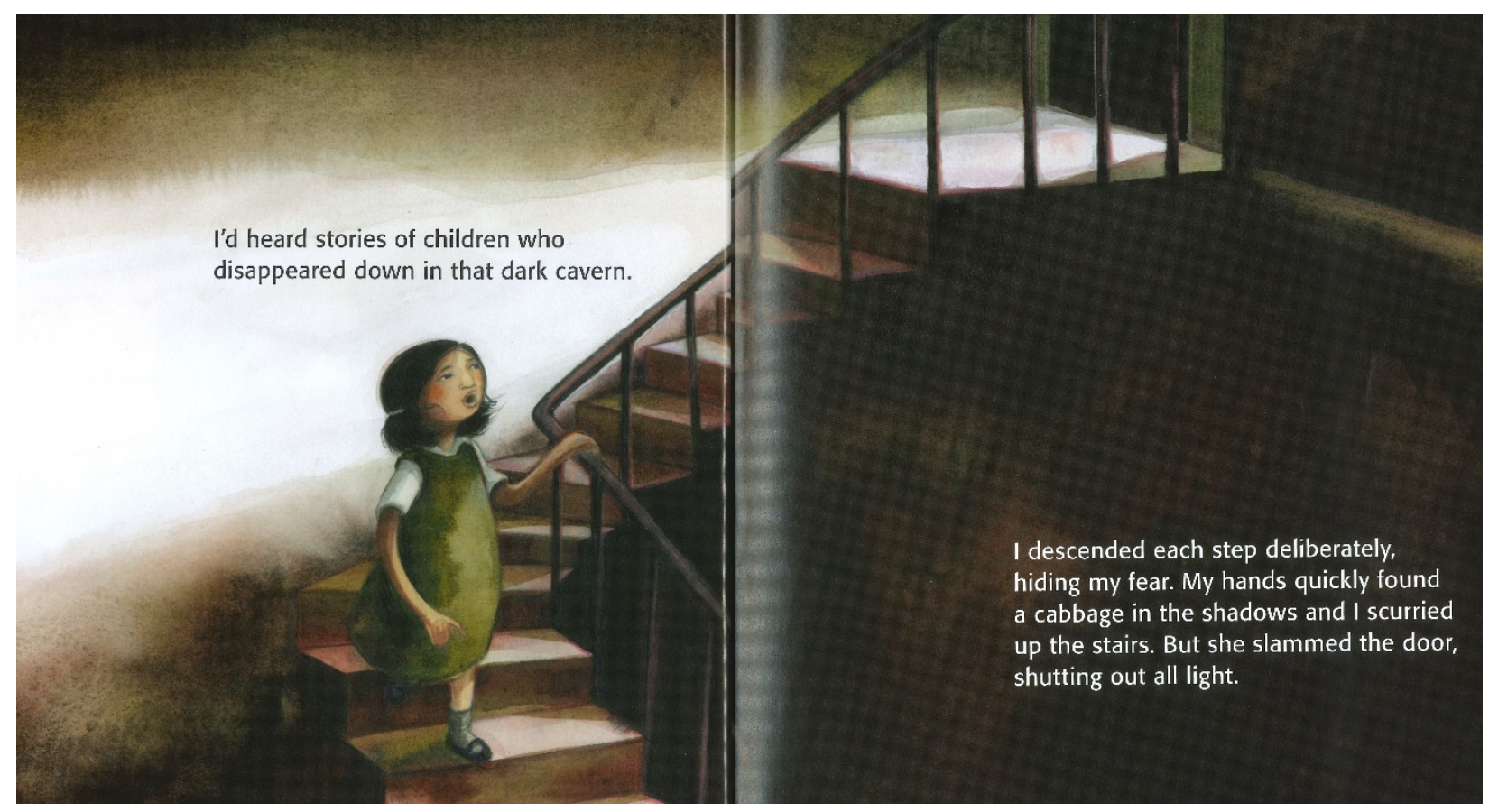

Fig. 6. Olemaun descending a staircase leading to the residential-school basement: Jordan-Fenton, Christy, Margaret Pokiak-Fenton, and Gabrielle Grimard. When I Was Eight. Annick Press, 2013.

Despite the nun's ceaseless efforts to break Olemaun's spirit, the child clings to her Indigeneity by summoning comforting memories of her Inuit home to overcome colonial oppression. When Olemaun realises the nun locked her in the basement, she reveals that "[a] scream built in my chest, but I held it in," indicating that while the harsh residential-school basement scares her, Olemaun does not succumb to fear (Jordan-Fenton, Pokiak-Fenton, Grimard). She remains calm by spelling words that evoke her Indigeneity—such as her Inuit name, "O-L-E-M-A-U-N," and her "distant home, B-A-N-K-S - I-S-L-A-N-D"-until she feels her father's pride and loving embrace (Jordan-Fenton, Pokiak-Fenton, Grimard). The act of spelling words rooted in her Indigeneity allows Olemaun to not only maintain her Indigenous identity but also progress towards accomplishing her goal of reading English. Grimard enforces 
how recalling her Indigeneity while trapped underground comforts Olemaun through her illustration of light-coloured words reminiscent of Olemaun's Indigenous home encircling her more closely than the surrounding darkness (see fig. 7). Olemaun herself is depicted with her eyes closed serenely and her arms crossed over her chest, mimicking the way "[father] wrapped his arms around me," a contrast of light and soft with harsh and dark that asserts how Olemaun's Indigeneity enables her to endure the nun's punishment (Jordan-Fenton, Pokiak-Fenton, Grimard). When she finally emerges from the basement, Olemaun admits that the nun's "angry black eyes raised goose bumps on the back of my shaved neck, but she could not make me cry," conveying how the composure Olemaun maintains while reflecting on her Inuit home prevents colonial nuns from erasing her Indigeneity (Jordan-Fenton, Pokiak-Fenton, Grimard). Neither colonial attempts to remove physical reminders of Olemaun's cultural origins, such as shaving off her black braids, nor punishments intended to silence memories of home can make Olemaun forget her Inuit identity. Olemaun's ability to draw on her previous positive exposure to individuals who express pride in their Indigenous culture, like her father, tethers Olemaun to her Inuit identity throughout her residential-school experience (Barnes and Josefowitz 69). Grimard conveys how Olemaun's Indigeneity empowers her to remain strong against colonisers that attempt to suffocate her identity by juxtaposing Olemaun's tranquil face and light-coloured words about her home with the imposing blackness around her. 


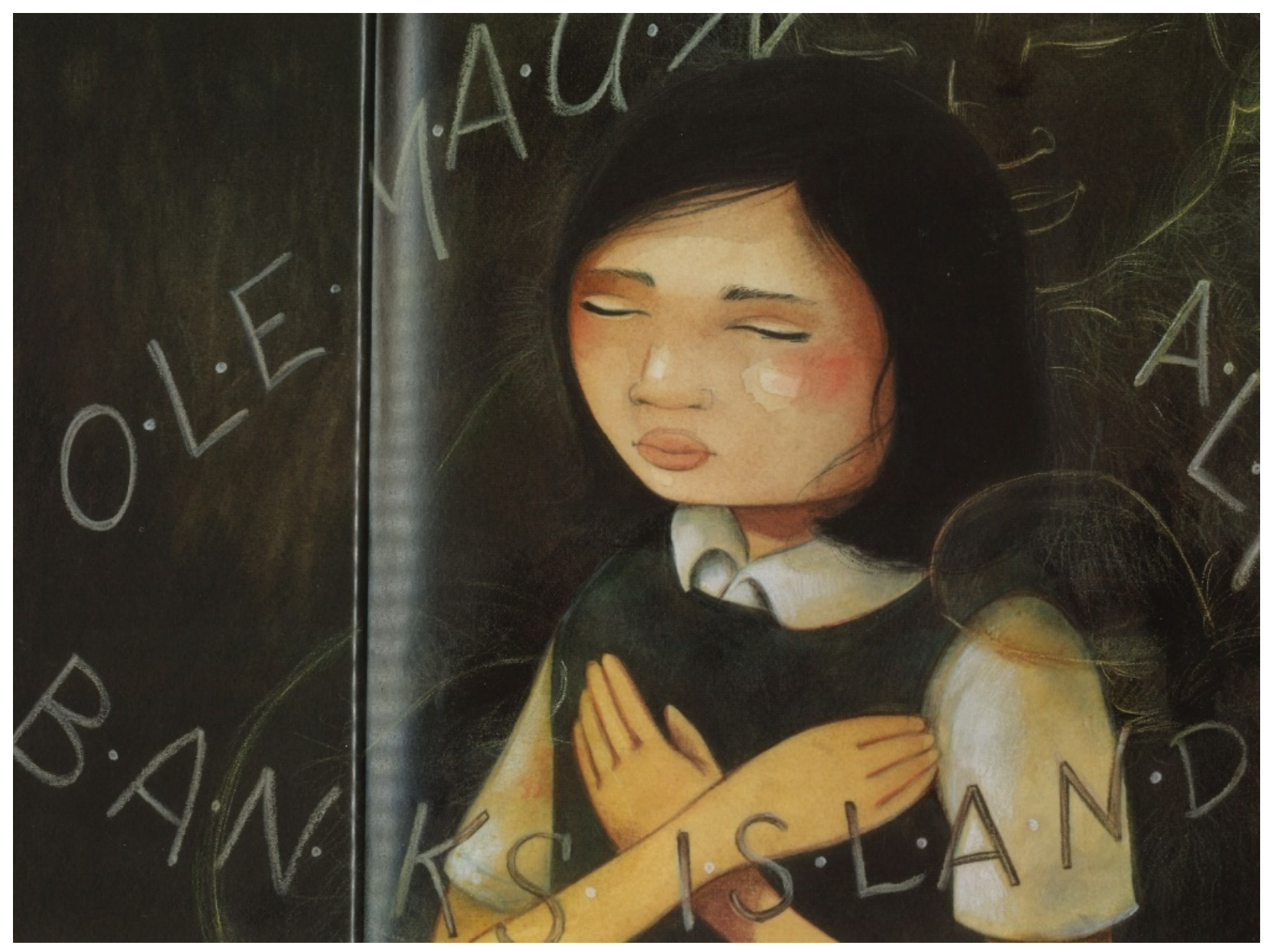

Fig. 7. Olemaun locked in the residential-school basement: Jordan-Fenton, Christy, Margaret Pokiak-Fenton, and Gabrielle Grimard. When I Was Eight. Annick Press, 2013.

\section{Stolen Words}

Unlike A Coyote Columbus Story or When I Was Eight, the primary action in Stolen Words occurs in postcolonial Canada and explores the lasting rather than immediate effects of colonisation. Florence's story centres on a Cree girl and her grandfather who rediscover their lost Indigenous language together after the grandfather explains that he forgot Cree because, many years ago, colonists forced Indigenous children like him to attend residential schools where they were permitted to speak only English. The next day, when the grandfather arrives to collect his granddaughter from school, she gleefully presents him with an Introduction to Cree dictionary 
de Liberato 35

while speaking the Cree word for "grandfather." As he flips through the dictionary, the grandfather's stolen words return to him, and he promises to teach his granddaughter Cree.

In Stolen Words, as in When I Was Eight, shapes and colours that help distinguish powerless Indigenous children from abusive colonists assert the value of Indigenous languages by portraying Cree as a medium for freeing Indigeneity oppressed by colonisation. Mirroring When I Was Eight, Grimard contrasts the rounded faces of Indigenous children with the angular face of a residential-school priest to enforce how colonists employ force to steal Cree from the students. While the granddaughter and residential-school boys are depicted with circular faces and soft features, Grimard illustrates the priest with a hooked nose, sharp jaw, and angular glasses. Even the priest's hands look unusually long and threatening (see fig. 8). The abrasive shapes distinctive of the priest's appearance enhance Florence's description of the men and women who run the residential school as people with "angry white faces" and "raised hands" by visually communicating their threat to the children's Indigenous language (Florence and Grimard). Grimard's illustration of the priest closely resembles her depiction of the vindictive nun from When I Was Eight and even reflects Monkman's portrayal of European explorers in A Coyote Columbus Story, with all three texts relying on similarly imposing shapes to represent colonists and symbolically establish them as dangers to Indigenous peoples. In her book Picture This: Perceptions and Composition, Molly Bang suggests that hard shapes-like the triangles that visually characterise colonists across all three Canadian texts - effectively evoke fear and aggression namely because "they are so pointy and sharp" (28). Pointy, sharp shapes connote other menacing objects like "knives, arrows, spears, missiles, rockets, and also rocky mountains" that "can easily pierce through our innards and kill us," making them ideal visual indicators of danger, such as that presented by European colonists (96). By employing a harsh priest who 
symbolically cages a raven — the embodied form of the children's Cree language — as a signifier for colonisers in Stolen Words, Grimard advances Florence's portrayal of residential-school instructors as evil men and women who forcibly oppress soft, powerless children.

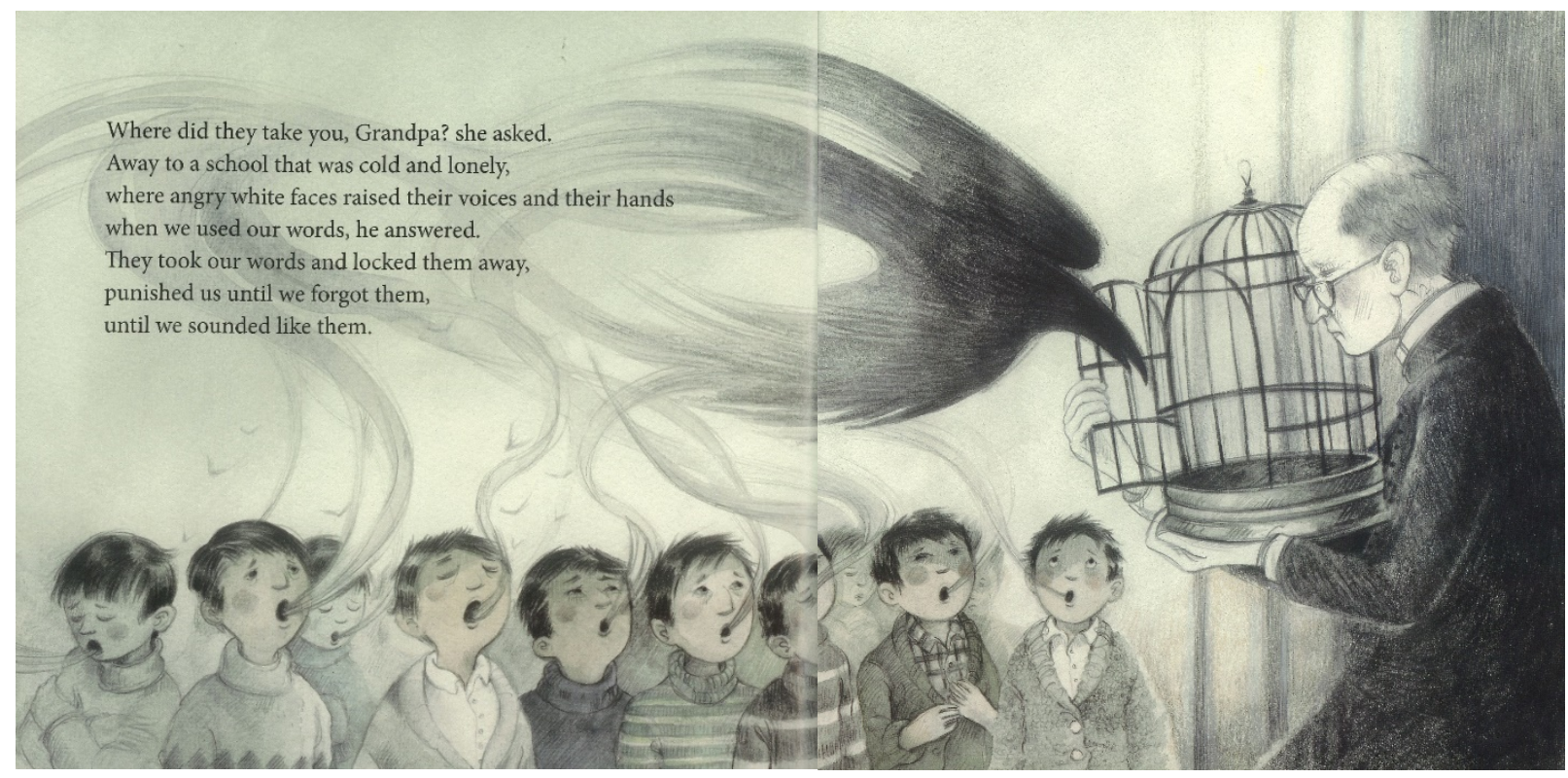

Fig. 8. A residential-school priest caging a raven born from the boys' Cree language: Florence, Melanie, and Gabrielle Grimard. Stolen Words. Second Story Press, 2018.

Through her use of othering language that distinguishes colonists from Indigenous children, Florence expands the grandfather's residential-school experiences to include all Indigenous children from Canada subjected to similar abuses. The grandfather introduces colonists to his granddaughter as "they," a vague pronoun that denies the men and women responsible for stealing the grandfather's Cree any specific identity (Florence and Grimard). "They" is also an exclusionary pronoun, as it denotes a group from which the speaker is exempt. While denying people's names dehumanises them, the grandfather also fails to call his own people by name, referring to other Cree boys at the residential school as "us," just as he groups colonisers together under the moniker "they." But "us" functions opposite to "they," asserting the speaker's membership within a specific group. Through this othering language, the text 
enforces conflict between the two opposing groups, where "they" are the perpetrating colonisers acting against "us," the Indigenous child victims. In writing about colonisation from the position of the oppressed, works like Stolen Words challenge oppressive colonial ideologies that ostracise the Other: "that which is opposite to the person doing the talking or thinking or studying" (Nodelman 29). As a text that foregrounds the personal, familial, and cultural significance of reclaiming a stolen Indigenous language, this picture book transfers the power to talk, think, or study the European colonisation of Indigenous peoples in Canada to Florence, making colonists the subject of consideration and, thus, the Other or "them." By establishing colonisers as a monolithic threat to Indigenous languages, Stolen Words addresses all residential-school victims who endured abuse intended to silence their Indigeneity and gives them a voice once more.

Grimard uses contrasting colours to advance the juxtaposition Florence establishes between colonisers or colonial environments and Indigenous peoples or places by dramatizing malicious colonial desires to destroy Indigenous cultures, families, and identities. Florence and Grimard immediately establish Indigeneity as colourful, joyful, and loving by presenting the granddaughter dancing with a dream catcher on the picture book's first pages (see fig. 9). The dream catcher, an Indigenous craft intended to comfort and protect, features "[b]its of string. Plastic beads. And brightly coloured feathers" that Grimard highlights at the top, centre of her illustration (Florence and Grimard). This portrayal of Indigeneity starkly contrasts Florence's description of colonisers as "[m]en and women dressed in black" at a "school that was cold and lonely" (Florence and Grimard). Grimard helps establish the residential school as an unwelcoming environment by illustrating it in dark, faded colours. While Grimard's double spread of the school depicts a priest in black and white, suggesting he lacks life and vibrancy, she illustrates the Indigenous children in sweaters of varying washed-out colours, conveying how 
the colonists' school leaches the boys of their vivid Indigeneity. The soft, realistic colours Grimard employs to illustrate Stolen Words and When I Was Eight differ drastically from the psychedelic hues that predominate in A Coyote Columbus Story. Bang explains that "[w]e associate the same or similar colours much more strongly than we associate the same or similar shapes," meaning that the juxtaposing shapes used to visually separate Indigenous peoples from colonists in each Canadian text become a significantly more impactful tool for contrasting Indigenous and non-Indigenous characters when they are grouped according to like colours (106). Because dark colours evoke inherently negative associations, such as death or emptiness, and light colours typically generate positive feelings, such as joy or excitement, Grimard and Monkman's consistent use of warm colours to signify Indigenous peoples and dark or disorienting colours to denote colonists helps convey an Indigenous, non-Indigenous juxtaposition that generates sympathy for Indigenous characters and hostility towards colonial characters (92). Consequently, Grimard's pairing of round shapes with gentle hues when illustrating Indigenous peoples and pointy shapes with dark shades when depicting colonists dramatically distinguishes powerless Indigenous children from cruel residential-school instructors in Stolen Words and When I Was Eight. Similarly, Monkman's combination of naturalised shapes and colours for images of Indigenous peoples and hyperbolic shapes and colours for portrayals of European explorers in A Coyote Columbus Story intensifies a visual contrast between rational Indigenous and greedy non-Indigenous characters. By juxtaposing colourful Indigenous peoples and environments with bland colonial ones, Stolen Words conveys how colonisation threatens to destroy Indigenous cultural vibrancy. 


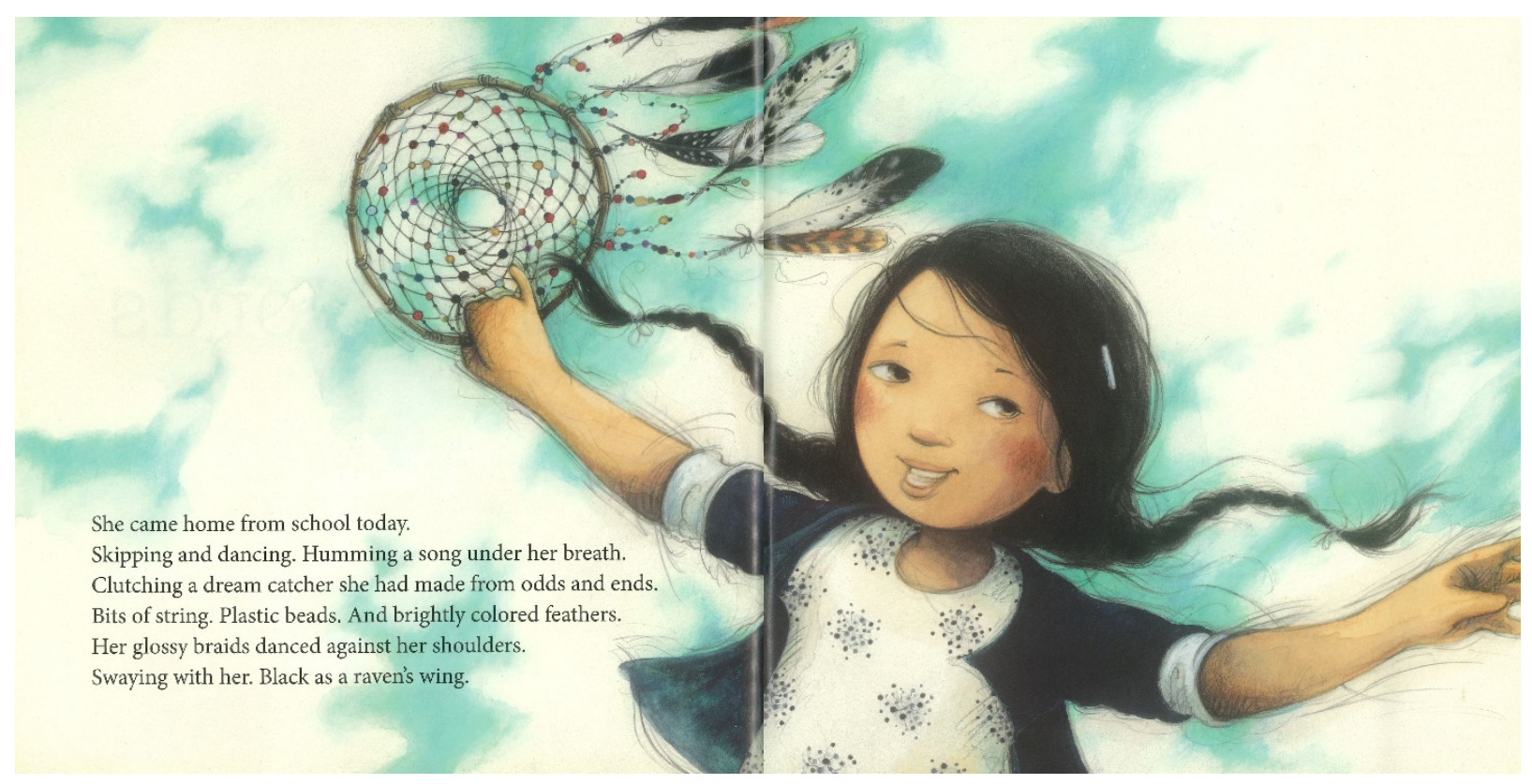

Fig. 9. A Cree girl dancing with a dream catcher: Florence, Melanie, and Gabrielle Grimard. Stolen Words. Second Story Press, 2018.

Grimard further asserts how Indigenous languages can restore cultural losses resulting from colonisation in her visual rendering of the grandfather remembering Cree. As the grandfather turns the pages of his Introduction to Cree dictionary, ravens break free from the cage illustrated within, and a different Cree word trails behind each raven (see fig. 10). Grimard introduces the black raven — a symbol of metamorphosis in some Indigenous cultures—in her illustration of the residential school, presenting it as a physical manifestation of the children's stolen Cree words and, thus, directly associating it with colonial endeavours to erase Indigenous cultures. In each of her images after the grandfather first opens the dictionary, Grimard depicts the black ravens against colourful skies, contrasting a dark reminder of colonialism with a beautiful setting. This juxtaposition presents the ravens as a medium through which the grandfather frees his repressed Indigeneity, enhancing Florence's textual exploration of how reclaiming Cree words enables the grandfather to invoke his Indigenous home and family: "The 
word felt familiar in his mouth. It felt like his home. His mother" (Florence and Grimard).

Barnes and Josefowitz's research supports the grandfather's association between the Cree language and his Indigenous home and family, indicating that the ability for residential-school victims to continue practicing their Indigenous languages, even secretly, enhances their psychological resiliency, strengthening them against the detrimental effects of colonisation by preserving a link to their cultural origins (71). Small ravens remain near the grandfather and granddaughter as they walk home while the sun sets, suggesting an enduring and inescapable connection between Indigenous language and colonialism, one in which vast, colourful settings that connote the unique vibrancy of Indigenous cultures ultimately triumph. By opposing black ravens that signify Cree language stolen by colonists with a colourful environment that reflects the grandfather's joy, Grimard emphasises how rediscovering Cree allows the grandfather to embrace his Indigenous culture again and share it with his granddaughter.

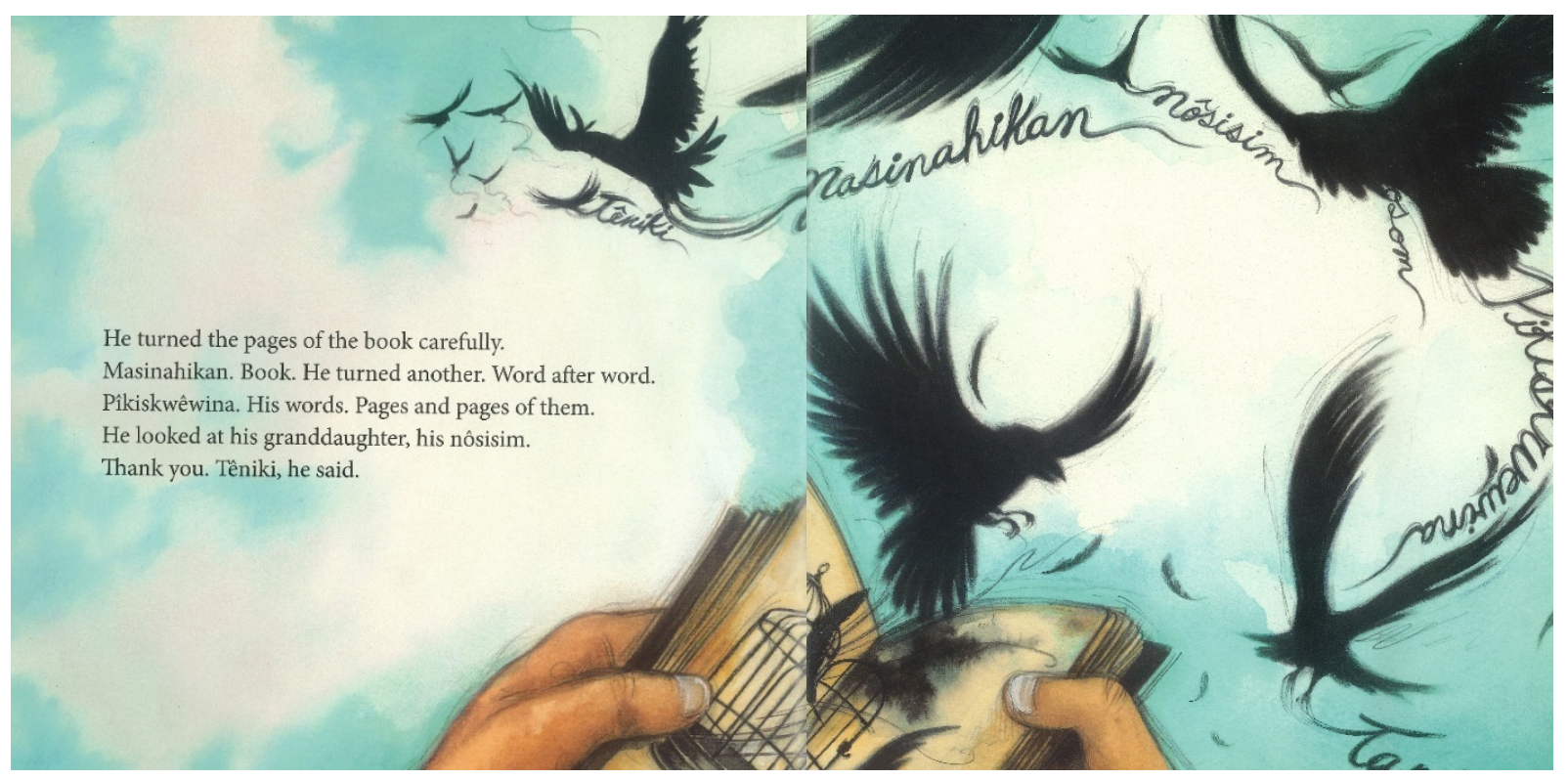

Fig. 10. Ravens bursting from an Introduction to Cree dictionary: Florence, Melanie, and Gabrielle Grimard. Stolen Words. Second Story Press, 2018. 


\section{AUSTRALIAN PICTURE BOOKS}

\section{The Rabbits}

The Rabbits mirrors A Coyote Columbus Story in both content and style, drawing on postmodern literary and artistic techniques to confront European representations of Australian colonisation. The text explores how British colonisation has impacted the country's Indigenous inhabitants for over two centuries, with numbat-like creatures native to Australia representing Aboriginals and white rabbits signifying colonisers. Marsden and Tan deliberately select rabbits to embody British colonisers because Thomas Austin imported twenty-four wild rabbits to Australia from England in 1859 (Iannella, Peacock, Cassey, and Schwensow 604). Since all potential predators failed to recognise the rabbits as food, Australia's rabbit population skyrocketed into the hundred-millions, resulting in significantly reduced vegetation across the country (603-604). This historical context combined with textual portrayals of colonists destroying natural Australian environments with pollutive Western technology establishes European rabbits as an invincible threat to Indigenous landscapes. An unidentified numbat narrates The Rabbits, conveying the abuse endured by Aboriginals because of colonisation, including illness, violence, forced migration, and government-mandated assimilation.

The Indigenous and non-Indigenous juxtaposition in The Rabbits distinguishes natural native numbats from technological foreign rabbits to assert the importance of cultivating respectful relationships with the land. Upon their first meeting, the numbats describe the rabbits as looking only "a bit like us," suggesting they share few physical similarities (Marsden and Tan). Marsden's immediate emphasis on the extent of difference separating the numbats from the rabbits evokes an "us versus them" mentality like the grandfather's in Stolen Words. Using opposing shapes and colours, Tan enhances these differences by depicting the numbats with 
curling tails, rounded backs, and brown exteriors, all of which connote proximity to the land (see fig. 11). According to Bang, curves—like those that characterise the numbats—often evoke comforting maternal bodies and consequently generate feelings of security (98). The rabbits, by contrast, are illustrated with pointed ears and feet, "ramrod straight backs" that "lend an air of grotesque rigidity to their appearance," perfectly white fur, and human clothes to enforce their distance from nature (Nabizadeh 42). Additionally and importantly, earth occupies most of this image, presenting land as the foundation of Indigenous lifestyles. Tan includes a pair of indentations from the rabbits' coach dissecting this golden terrain, alluding to the destructive toll rabbit technology will wreak on Australia's unique environment. The narration also appears in a hand-written script that combines upper- and lowercase letters rather than a uniform typeface to further advance Tan's visual conflation between the numbats and nature. This childlike scrawl suggests that numbats possess a juvenile understanding of the written word, further distinguishing them from the rabbits, who display an obsession with recording everything they encounter in Australia. By visually distinguishing the numbats from the rabbits using contrasting shapes and colours that convey the numbats' oneness with the land and the rabbits' rejection of it, Tan helps establishes an Indigenous, non-Indigenous juxtaposition synonymous with nature versus technology. 


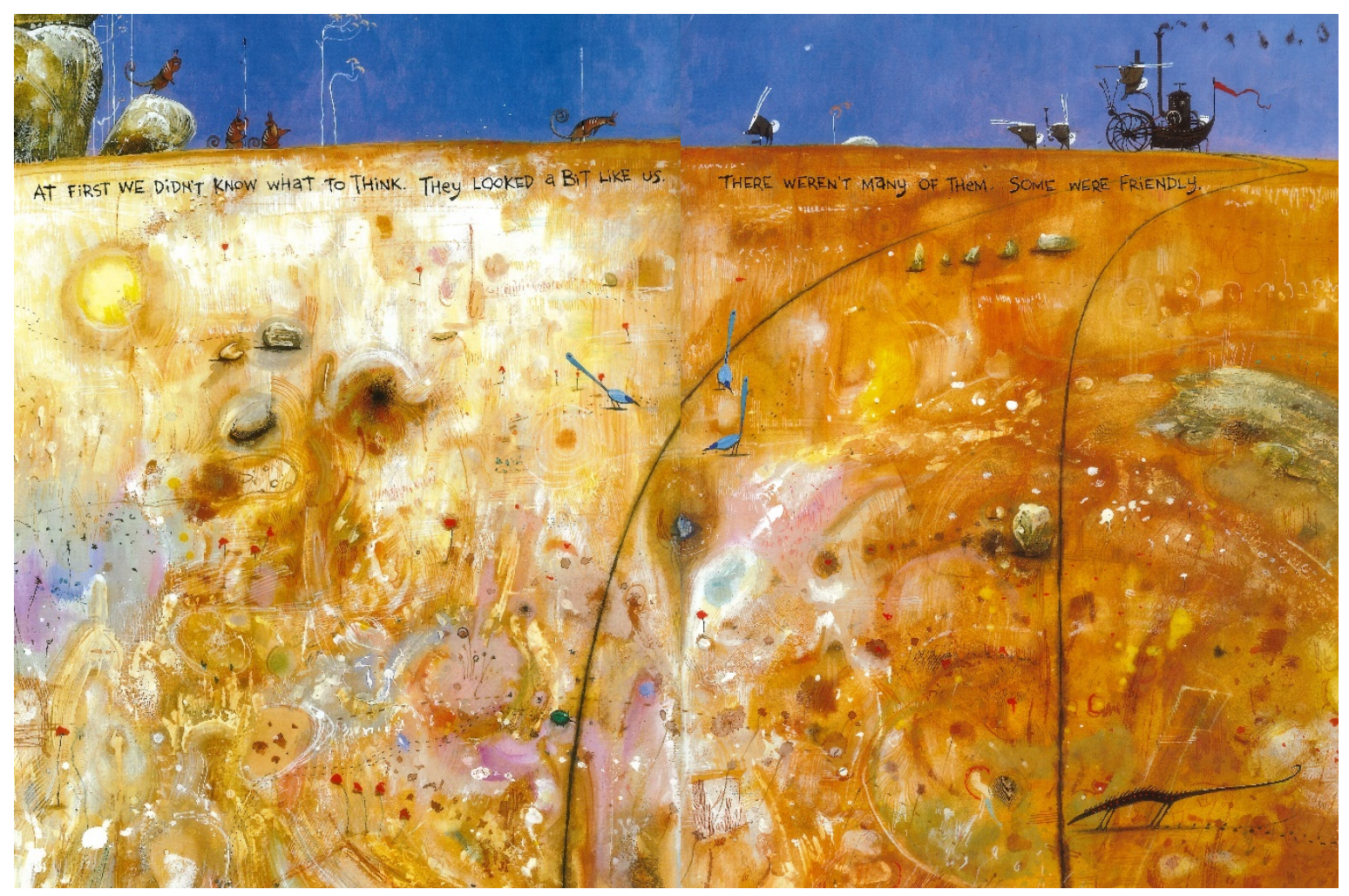

Fig. 11. The numbats meet the rabbits: Marsden, John, and Shaun Tan. The Rabbits. Hachette Australia, 1998.

Tan highlights differences between Indigenous and non-Indigenous environments through contrasting shapes and colours that present the rabbits as threats to numbat land. Though wild rabbits traditionally burrow in trees, these rabbits build houses using advanced machinery: "They didn't live in the trees like we did. They made their own houses" (Marsden and Tan). The rabbit houses resemble the rabbits themselves, their white, straight rectangular exteriors and pointed legs set against a colourful, rolling Australian landscape in the illustration's background to express an opposition between the rabbits and their natural surroundings (see fig. 12). This visual contrast between colours and shapes is an important illustrative tool because it "enables us to see" patterns, such as that established between Western colonial technology and deteriorating landscapes in this and subsequent images throughout The Rabbits (Bang 110). By rejecting their natural habitats in favour of artificial houses, the rabbits indicate that they neither need nor value 
land, allowing them to destroy Australia's environment without remorse. Tan juxtaposes the black smoke emitted by industrial rabbit machinery with white clouds in the sky and depicts a dead lizard flattened beneath the wheeled stand that supports a painting of the rabbits' housingdevelopment plan to visually convey how rabbit construction generates air pollution, disrupts the habitats of Australia's wildlife, and jeopardises animal safety. This fictional correlation between rabbit settlement and environmental decline alludes to the real "widespread damage to terrestrial ecosystems" resulting from Australia's rabbit surplus, "preventing regeneration of palatable native plants and supporting large populations of introduced predators" (Iannella et. al. 604). In other words, European rabbits overgrazed so excessively that Australia's vegetation and wildlife suffered drastically, negatively impacting Indigenous populations reliant on these resources for survival. By distinguishing the rabbits' fabricated homes from the numbats' natural ones using shapes and colours that disassociate the rabbits from nature, Tan foreshadows the looming death of Australia's pristine precolonial environment and ensuing destruction of traditional Indigenous lifestyles. 


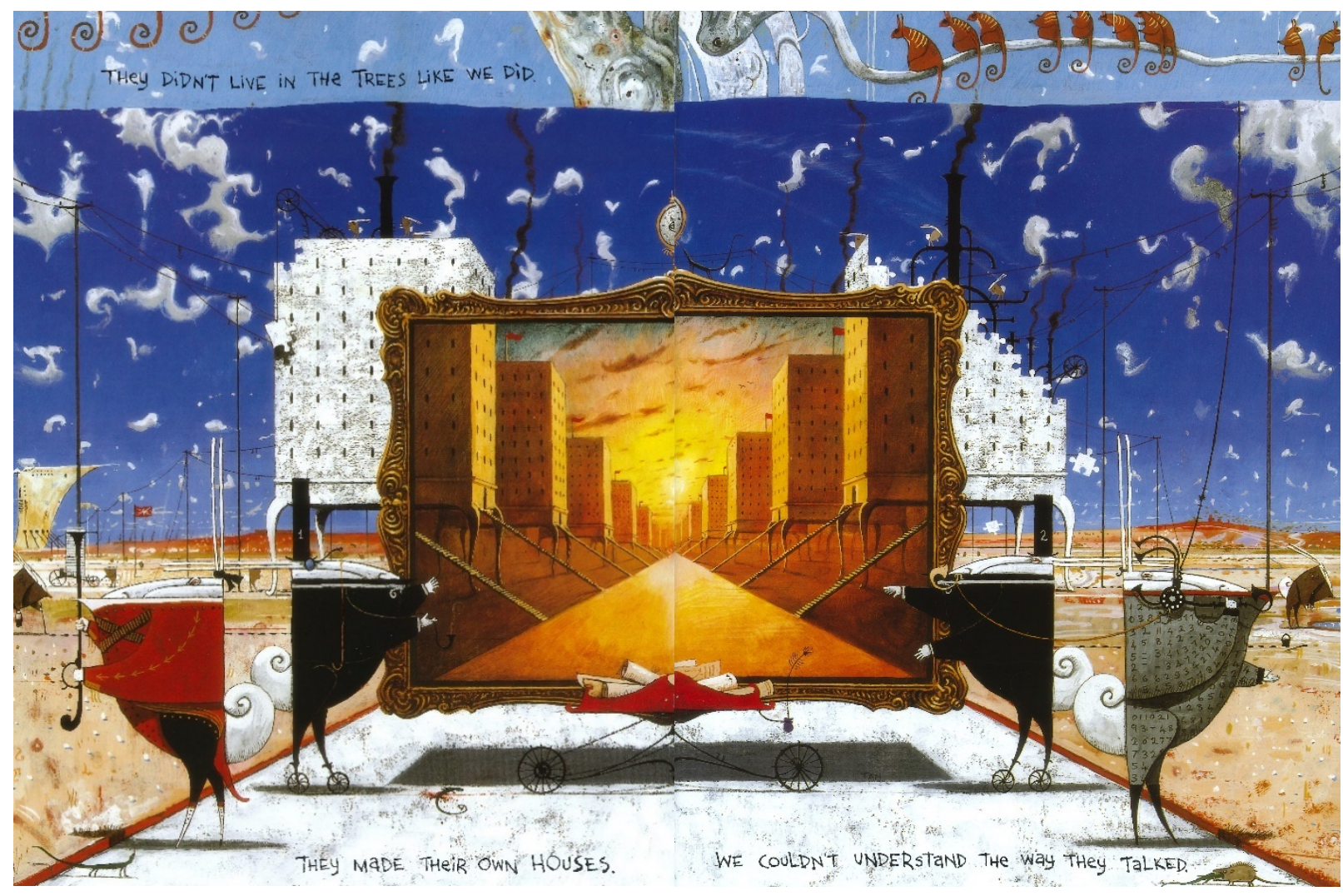

Fig. 12. The rabbits build houses: Marsden, John, and Shaun Tan. The Rabbits. Hachette Australia, 1998.

Tan illustrates rabbit machinery with increasingly harsh shapes to convey how colonial technology grows progressively more destructive throughout the text, hindering Indigenous landoriented lifestyles. As "[m]illions and millions" more rabbits settle in Australia and "spread across the country" until "[n]o mountain could stop them; no desert, no river," their industry dominates and devastates numbat land (Marsden and Tan). Tan juxtaposes dangerous rabbit technology with natural Indigenous environments in three separate images- - the first of rounded cliffs with precise indentations cut by rabbits to accommodate piping; the second of imposing machines that plow grass, chop down trees, and drive wildlife into hiding; and the third of a black-and-white rabbit city filled with identical rectangular buildings, one of which sucks away the blue, cloudy sky — to visually "memorializ[e] what is lost by making visible the abject nature 
of the processes of colonisation" (McGlasson 23, see fig. 13). Highlighting how colonial expansion depletes Australia's previously whole ecosystem, these illustrations explicitly relate rabbit industry with damaged numbat land. Subsequent images grow increasingly sparse as the land turns "bare and brown and the wind blows empty across the plains," indicating that frightening rabbit technology ultimately defeats inviting numbat environments (Marsden and Tan). Without the guiding influence of lush vegetation and wildlife, in which Leanne Betasamosake Simpson suggests human development is rooted throughout the Indigenous lifecycle, the numbats become disoriented, wondering where their once fertile home disappeared (Betasamosake Simpson 9). This colonial "destruction of land through resource extraction and environmental contamination....remove[s] Indigenous peoples from [their] homelands," jeopardising the persistence of Indigenous cultural traditions that rely on the land as pedagogy (Betasamosake Simpson 13-14). Tan's menacing depictions of the rabbit technology responsible for transforming Australia's previously lush environment into a wasteland leaves the numbats lost, stressing how colonisation endangers land-based Indigenous cultures. 


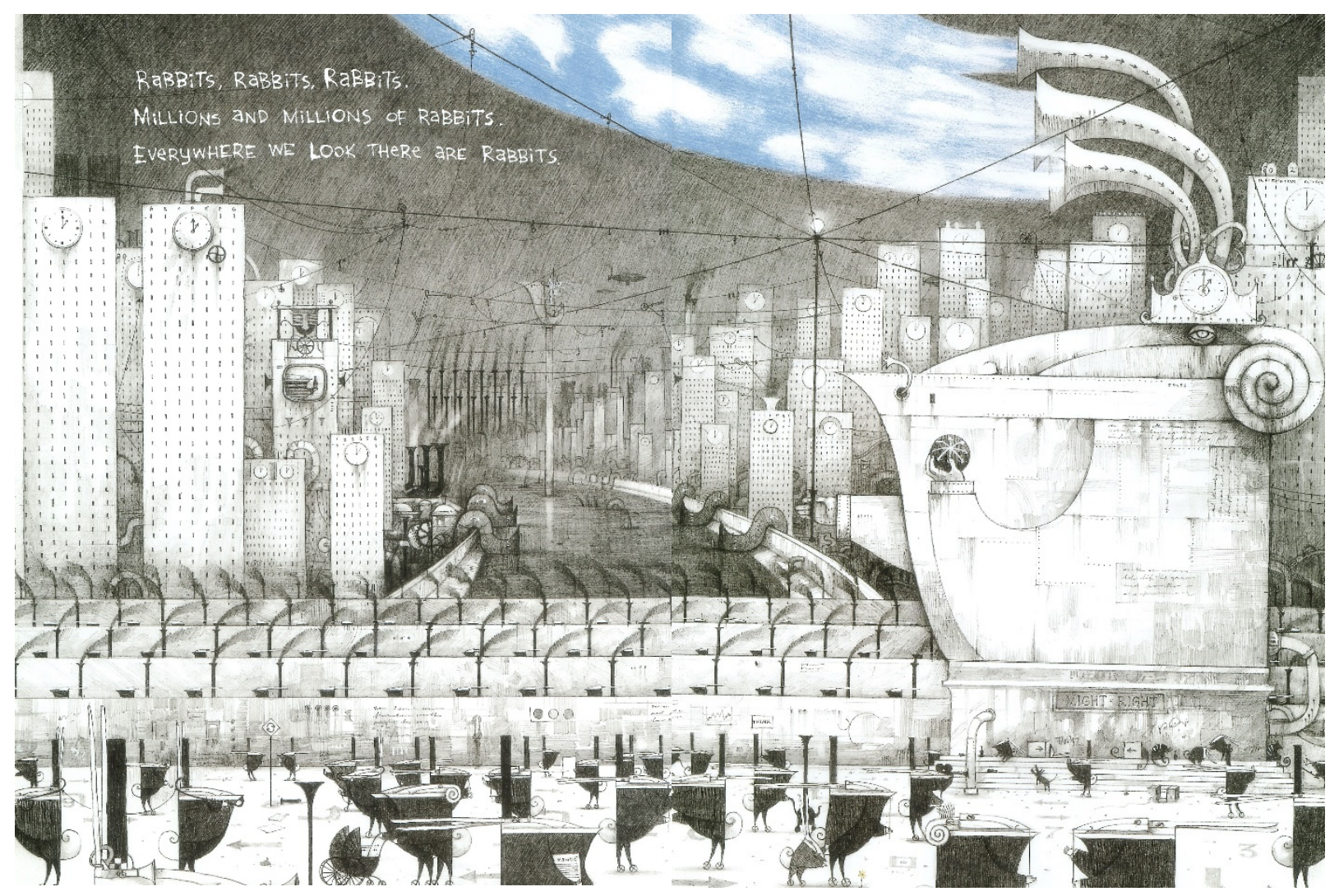

Fig. 13. The rabbit city: Marsden, John, and Shaun Tan. The Rabbits. Hachette Australia, 1998.

The expansive blue skies and warm, swirling earth that characterise Tan's illustrations of precolonial Australia vary drastically from his final black-brown depictions of barren landscapes, conveying how harmonious Indigenous relationships with nature support a healthy ecosystem ruined by colonisation. While the tall, portrait format of The Rabbits supports Tan's "epic" artworks, serving as an evocative canvas for this grand narrative about the decline of Australia's Indigenous environments that invites readers to discover new visual details with each rereading, it intensifies both the majesty of Tan's early images and the emptiness of his later ones (Nabizadeh 41). Tan depicts a rabbit contemplatively sifting dusty soil through his fingers in the bottom corner of an otherwise black page as the narrator asks, "Where is the rich, dark earth, brown and moist?" revealing that the rabbits recognise how their disregard for nature destroyed 
the land (Marsden and Tan, see fig. 14). Tan's final illustration of The Rabbits features a numbat and rabbit sitting across from one another separated by a small pool of water and surrounded by an endless expanse of technological debris with text that reads, "Who will save us from the rabbits?" indicating that the rabbits also need saving from themselves because their ceaseless industry left Australia barren (Marsden and Tan). The black border that frames this image connotes a polluted void into which the numbat expresses his concerns, enhancing his sense of helplessness and ultimately suggesting that no one can restore the desolate land (see fig. 15). Despite the impossibility of returning Australia's environment to its precolonial glory, Golnar Nabizadeh argues that the conclusion of The Rabbits acts as a subversive demand for reparations from the Australian government (37). These final dark, bleak illustrations juxtapose Tan's earlier colourful, rolling landscapes to assert how colonial disregard for nature causes irreparable environmental damage that denies Aboriginals the connectedness with land intrinsic to their cultural identities.

Like A Coyote Columbus Story, The Rabbits employs distinctly postmodern picture-book elements that address the fluidity of Indigenous temporalities to interrogate non-Indigenous representations of colonisation. Nabizadeh notes that "[a]lthough the story proceeds in a linear fashion, its temporal progression is truncated on several occasions to include references to the longer-term traumas that the arrival of the rabbits inflicts on the numbats, such as war, the erasure of traditional subsistence, and generations of stolen children" (37). By disrupting the mostly accurate timeline of The Rabbits with overlapping historical events — such as Tan's insertion of the same ship from his adaptation of E. Philips Fox's Landing of Captain Cook at Botany Bay, 1770 into the background of his illustration of rabbits building houses surrounded by telephone lines invented in the late-nineteenth century — intended to encapsulate the extent of 
colonial violence and oppression inflicted on Aboriginals in Australia over hundreds of years, the text loses some of its temporal coherency and consequently reflects the multiplicity of Indigenous temporalities. These non-sequential temporalities "exceed the forms of presentness posited and imposed through dominant modes of settler time" that accept only "a singular kind of temporal experience," enabling the merging of histories that characterises both $A$ Coyote Columbus Story and The Rabbits, in which clothing, technology, and experiences spanning multiple centuries blend together within the confines of a single story (Rifkin 37). According to Nabizadeh, "[t]he surreal construction of the world of [The Rabbits]" established by these shifting temporalities "draws attention to the constructed nature of representations, and the use of myths to power the colonial machine" (37). Consequently, readers of postmodern picture books like The Rabbits "are constantly reminded that the very (postmodern) process in which they are engaged is not so much clarifying the world for them... as much as immersing them in the problem of representation" (Allan 9). In other words, when picture books based in historical events, like The Rabbits and A Coyote Columbus Story, complicate time within the ontological realms of their stories, they call into question the accuracy of alternate stories reliant on settler time to convey the same histories. Through its postmodern convergence of multiple temporalities in images that combine events and objects from disparate historical periods, The Rabbits challenges non-Indigenous representations of the British colonisation of Aboriginals in Australia. 


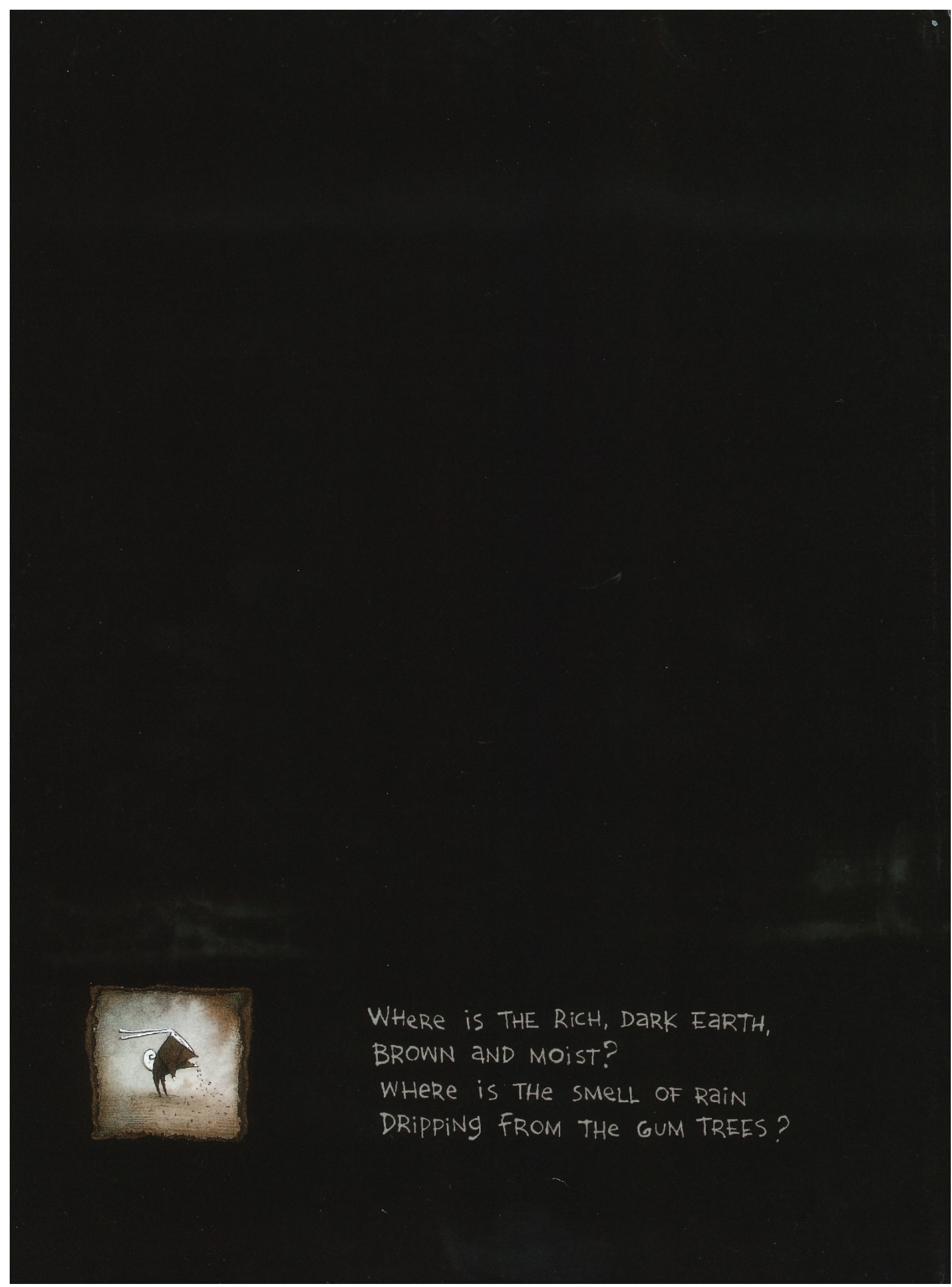

Fig. 14. A rabbit sifts dry earth through his fingers, surrounded by a black border: Marsden, John, and Shaun Tan. The Rabbits. Hachette Australia, 1998. 


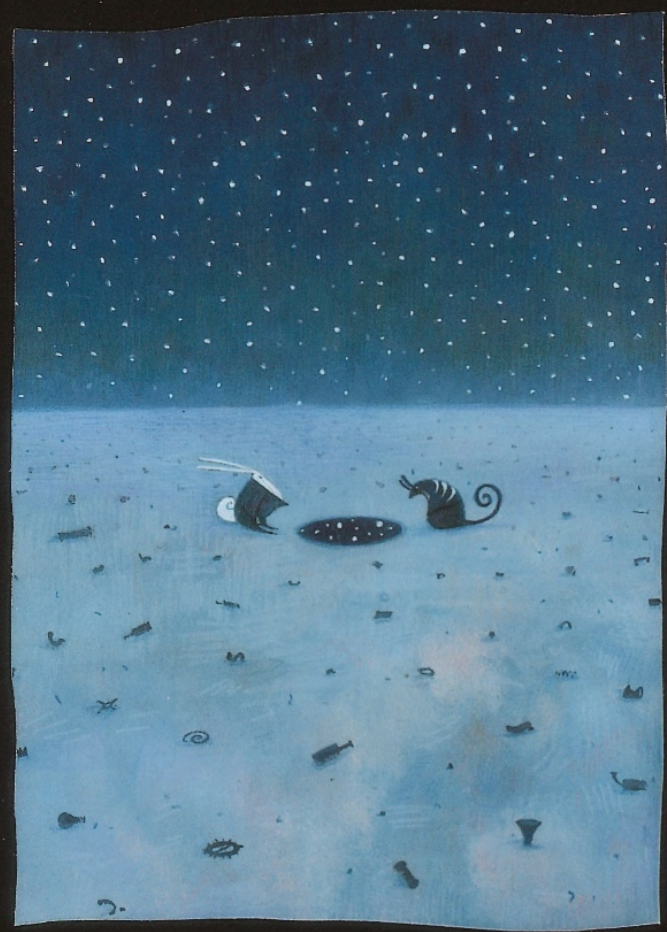

WHO WILL SAVE US FROM THE RaBBiTS?

Fig. 15. A rabbit and numbat divided by a small pool of water, surrounded by tools and stars: Marsden, John, and Shaun Tan. The Rabbits. Hachette Australia, 1998. 
de Liberato 52

\section{Stolen Girl}

Stolen Girl mirrors When I Was Eight in both artistic style and narrative content, its soft, muted illustrations differing significantly from Tan's bold acrylic paintings in The Rabbits. Introduced by a page of information about the Stolen Generation, Stolen Girl tells the story of a young Aboriginal girl taken to a children's home intended to reform Aboriginal youth. The girl survives the abuse, cold, and loneliness she experiences at the children's home by dreaming of returning to her simple house surrounded by a lush Australian landscape and practicing all the valuable skills she learned from her mother, including hunting, fishing, and swimming. When white families take older girls from the children's home to work as domestics, the story's protagonist devises a plan to avoid a similar fate by swimming away. After training herself to glide silently through a nearby river, the girl escapes early one morning and begins her journey home.

MacDonald employs warm, vibrant colours to establish the protagonist's home as a fertile landscape that encourages her connection with Indigenous cultural practices. The girl's description of a typical day at home indicates that she and her mother depend on the land for survival: "Her mother took her to the river every day and taught her how to fish and swim. As they walked, she learnt how to hunt goanna. On the way home, they would collect sugarbag honey from the eucalyptus trees" (Saffioti and MacDonald). Every aspect of the girl's day is rooted in Australia's natural environment, positioning the land as an intrinsic part of her life. The scene wherein "the girl would play with a family of lizards" every afternoon conveys a symbiotic relationship between the girl and Australia's wildlife in which she expresses her appreciation for the environment and coexists peacefully within it (Saffioti and MacDonald). The respectful way 
the girl engages with her natural surroundings emerges from Indigenous ideologies that suggest the land possesses the same capacity for feeling as any sentient being:

Country in Aboriginal English is not only a common noun but also a proper noun. People talk about country in the same way that they would talk about a person: they speak to country, sing to country, visit country, worry about country, feel sorry for country, and long for country. [...] Because of this richness, country is home, and peace; nourishment for body, mind, and spirit; heart's ease. (Bird Rose 7)

Aboriginals acknowledge that the land depends on human empathy to produce the sustenance necessary for their survival. Consequently, the protagonist and her Indigenous environment coexist in a reciprocal cycle of giving that protects and enriches the health of both parties. MacDonald further conveys the protagonist's oneness with nature through her accompanying illustration of this scene in which the girl and her mother walk along a bright river lined with lush trees as they carry baskets of plants against a vivid orange sky (see fig. 16). The rich colours that dominate this image connote heat and comfort, enhancing the girl's fond memory of her Indigenous home and family. These early illustrations juxtapose MacDonald's depictions of the colonial children's home as a desolate environment that represses the protagonist's Indigeneity. 


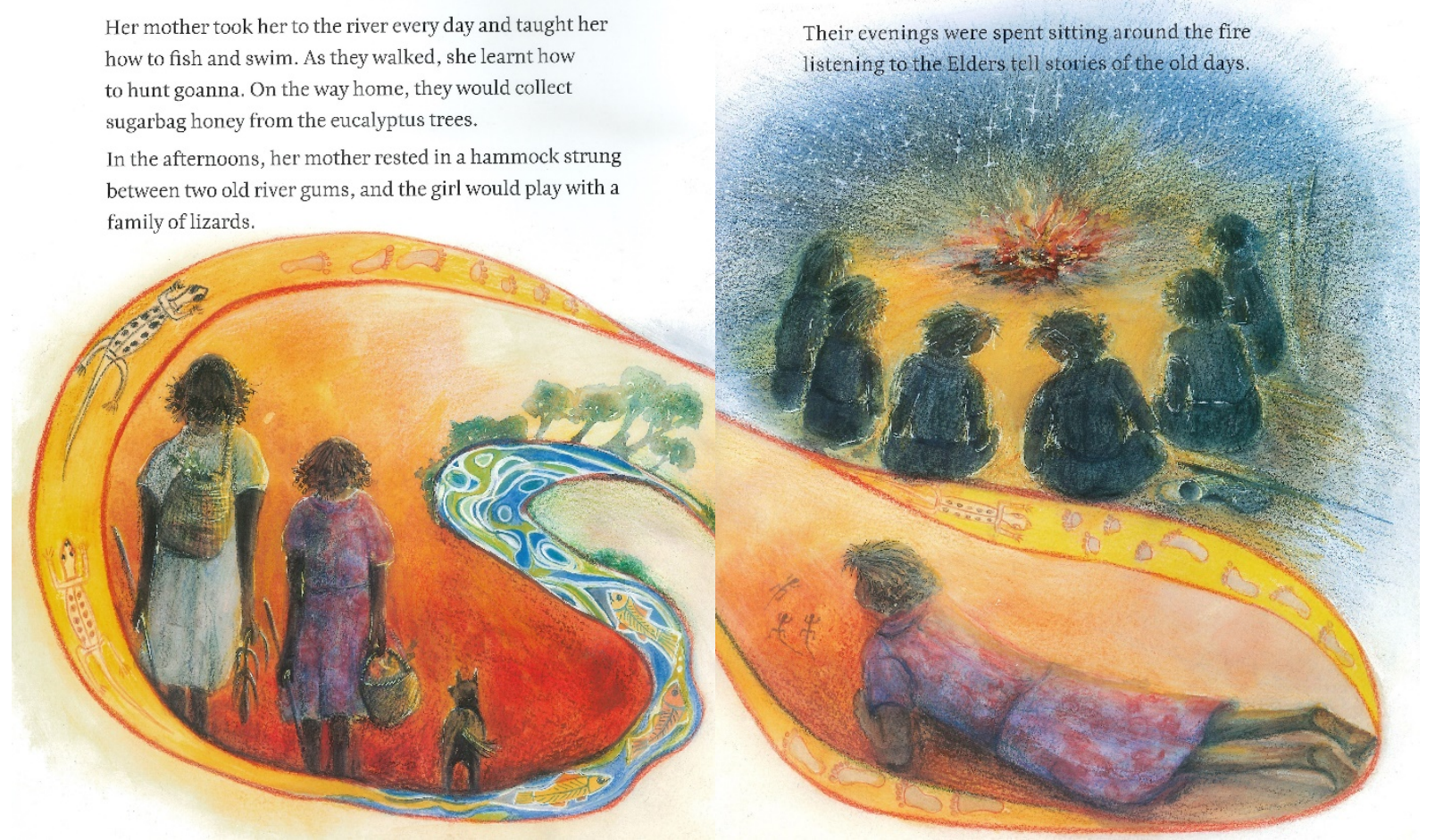

Fig. 16. The girl in her Indigenous home: Saffioti, Trina, and Norma MacDonald. Stolen Girl. Magabala Books Aboriginal Corporation, 2011.

MacDonald's subdued illustration of the protagonist and her peers from the children's home performing their exercises outside in winter conveys how colonists jeopardise the girl's Indigenous relationship with the land by subjecting her to harsh environments. Saffioti suggests that the protagonist's encounters with nature at the children's home harm rather than empower her: "Winter comes and the girls are made to do their exercises in the yard. Shivering, they huddle together trying to get warm" (Saffioti and MacDonald). Colonists force the girl to endure inclement weather that transforms nature from a source of food, warmth, and friendship into a source of pain, reducing her positive associations with the land. This scene reflects recent studies conducted by the Nuu-chah-nulth researchers' group, which indicate that most Aboriginal children who attended government missions suffered adverse physical conditions in addition to 
separation from their families, loss of native language, child labour, sexual abuse, spiritual abuse, emotional abuse, and, most frequently, physical abuse (Walters 134, 144). MacDonald's use of faded, monotone colours in her depiction of the protagonist crying as she stretches towards a cold sky while wearing a dirty white dress positions the colonial children's home as a hostile environment that starkly opposes the girl's nurturing Indigenous home and, thereby, threatens her harmonious connection with nature (see fig. 17). Through opposing warm and cold colours that separate Indigenous and colonial environments, MacDonald enhances Saffioti's portrayal of the children's home as a colonial force capable of destroying Indigenous relationships with the land.

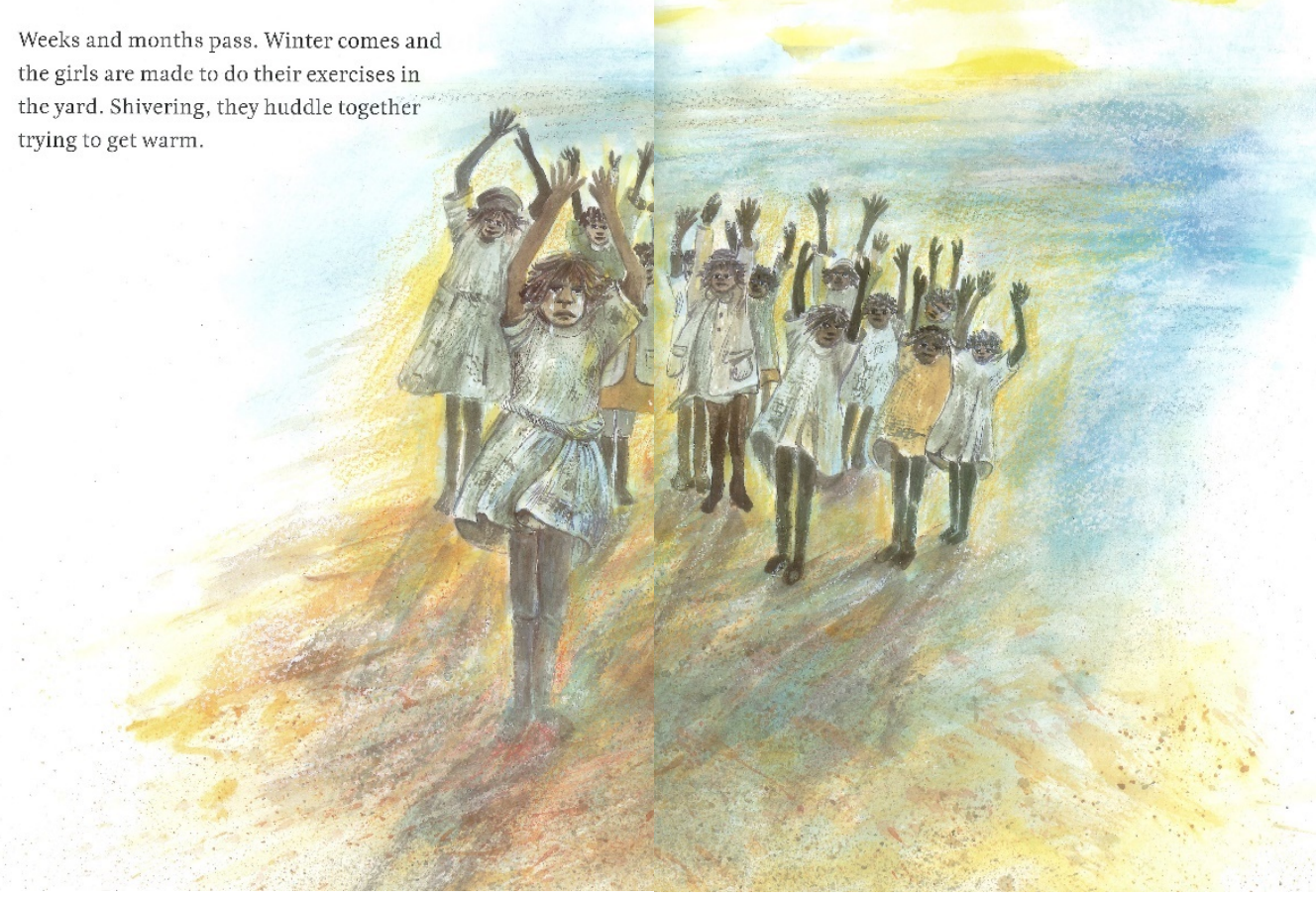

Fig. 17. The girl and other students from the children's home performing their daily exercises outdoors in winter: Saffioti, Trina, and Norma MacDonald. Stolen Girl. Magabala Books Aboriginal Corporation, 2011.

MacDonald further contrasts Indigenous and colonial environments through juxtaposing flowing and constrictive shapes that visually emphasise how the children's home limits the 
protagonist's connection with nature. When she imagines home, the girl dreams of performing acts that connote gentle affection, such as "running into her mother's arms," singing soft songs that echo "off the desert sand," and snuggling close to her mother (Saffioti and MacDonald). MacDonald's accompanying illustrations of the protagonist's fantasies feature an expansive sky of swirling brushstrokes that envelope the girl and her mother, reflecting the comfort she associates with her Indigenous life. Conversely, after a colonist drags the protagonist by the wrist away from her mother and into his car, she "sat silently, hoping that if she was very still he would forget she was there," indicating that her initial exposure to colonial forces encourages the girl to limit herself (Saffioti and MacDonald). MacDonald positions close and distant images on facing pages, one of which juxtaposes a vibrant landscape as seen through the car window with the bleak interior of the vehicle itself, to stress how colonisation traps the girl in an environment unlike her Indigenous home (see fig. 18). Children's home instructors further bar the girl from her cultural origins when they "took away the clothes that her mother had sewn, and gave her a faded dress someone else had worn" and "have given her a new name," confining the protagonist within a colonial setting by systematically removing signifiers of the girl's Indigeneity (Saffioti and MacDonald). This method of acculturation echoes the Canadian picture book When I Was Eight, with both stories portraying colonists at government institutions taking clothes and names from Aboriginal children "to force their students to abandon Aboriginal spiritual and cultural practices" (Barnes and Josefowitz 66). MacDonald frames three images of the protagonist's introduction to colonial environments in circular shapes that connote entrapment to emphasise how the children's home reduces her access to Indigenous land. Bang posits that illustrations in which shapes overlap or dominate the page feel claustrophobic because "[s]pace implies time" (126). Consequently, MacDonald's depictions of vast Indigenous landscapes connote endless 
time and freedom while those of enclosed colonial spaces feel imminent and threatening. By opposing swirling shapes that convey the boundlessness of the protagonist's Indigenous home with restrictive shapes that emphasise how the children's home polices her contact with nature, MacDonald enforces that colonisation jeopardises the girl's relationship with Australia's rich environment.

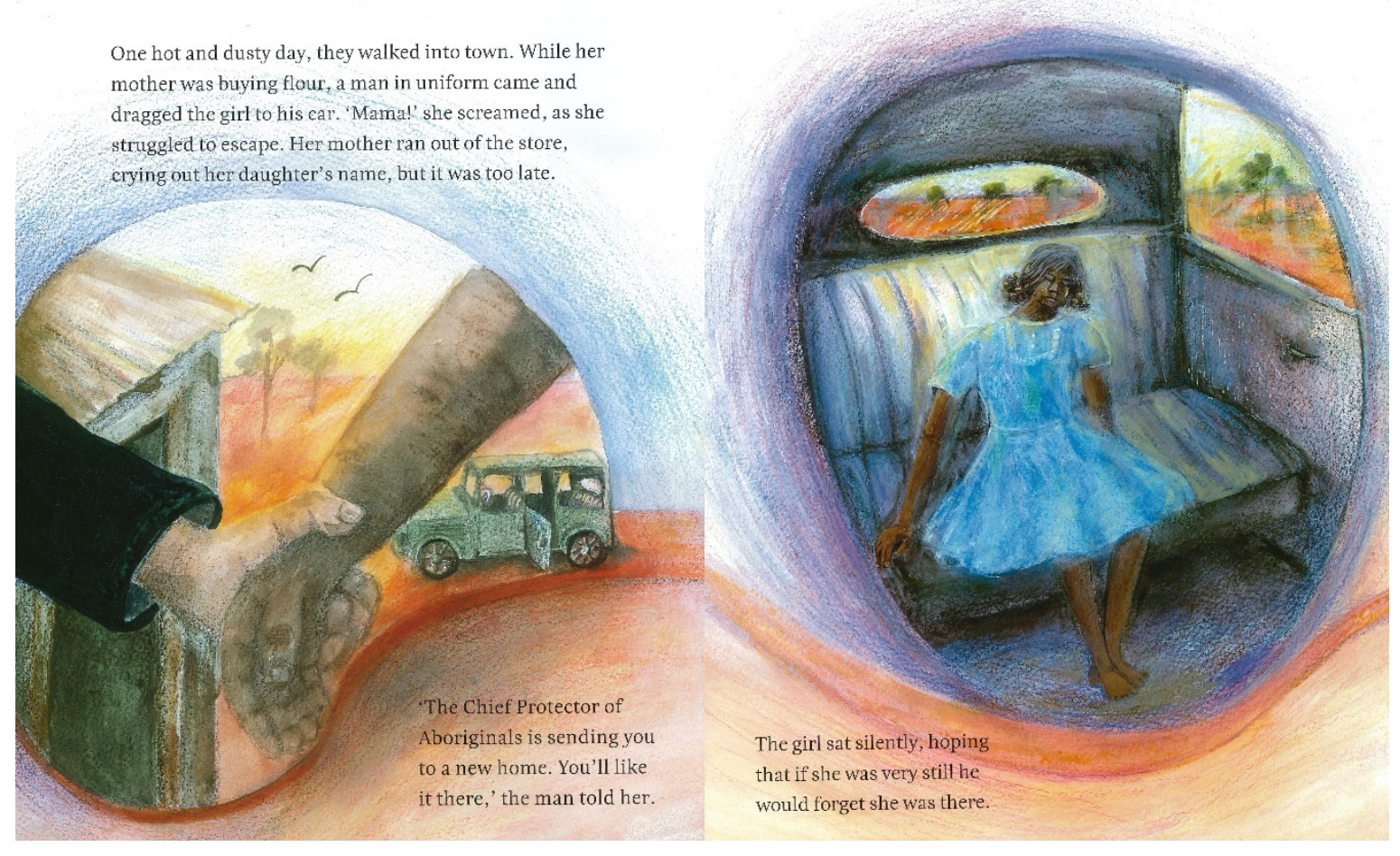

Fig. 18. A colonist kidnaps the girl from her Indigenous home with his car: Saffioti, Trina, and Norma MacDonald. Stolen Girl. Magabala Books Aboriginal Corporation, 2011.

MacDonald celebrates the protagonist's reconnection with Indigenous land through colourful illustrations of her reunion with nature that contrast images of the children's home's bleak interior. Warm, vibrant colours predominate MacDonald's depiction of the girl sneaking away from the schoolroom to practice "gliding beneath the surface of the water, barely making a ripple," indicating that the protagonist's willful engagement with nature once "[t]he weather gets warmer" enables her to overcome the trauma she associates with exercising outdoors during 
winter and restores her relationship with the land (Saffioti and MacDonald). Saffioti suggests that the girl's plan to escape from the children's home by swimming through a nearby river increases her oneness with nature when the protagonist expertly disguises herself within it in her bid to reclaim her Indigenous home and family. MacDonald advances this sense of unity between the girl and land by matching the colour of her dress to the colour of the water, evoking a strong physiological association between the serene river and the girl as she enters it (Bang 42, see fig. 19). As one of only two illustrations with no white space in Stolen Girl, this image emphasises the protagonist's complete immersion in nature free from colonial interruption. Two subsequent illustrations of the empty gray, brown hallways of the children's home directly oppose the orange landscape that awaits the protagonist as she escapes, highlighting the vibrancy of Indigenous environments to express how colonial attempts to stifle the girl's connection with the earth ultimately fail (see fig. 20). When MacDonald reintroduces warm colours into her image of the girl swimming in the river and walking into the sunrise, she suggests that the protagonist's reunion with Australian environments untouched by colonisation enables the girl's return to her Indigenous life. 


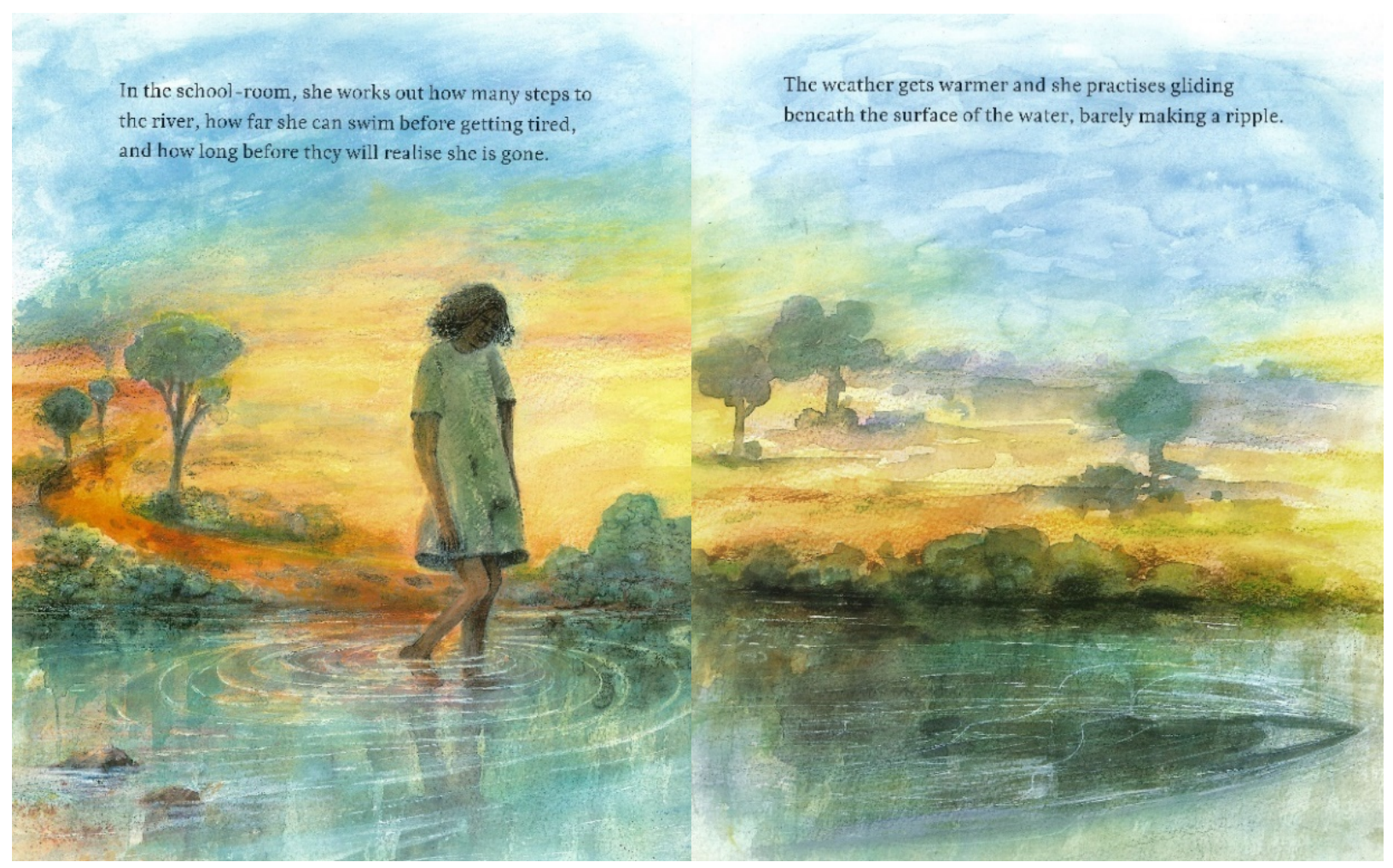

Fig. 19. The girl practices swimming in a river near the children's home: Saffioti, Trina, and Norma MacDonald. Stolen Girl. Magabala Books Aboriginal Corporation, 2011. 


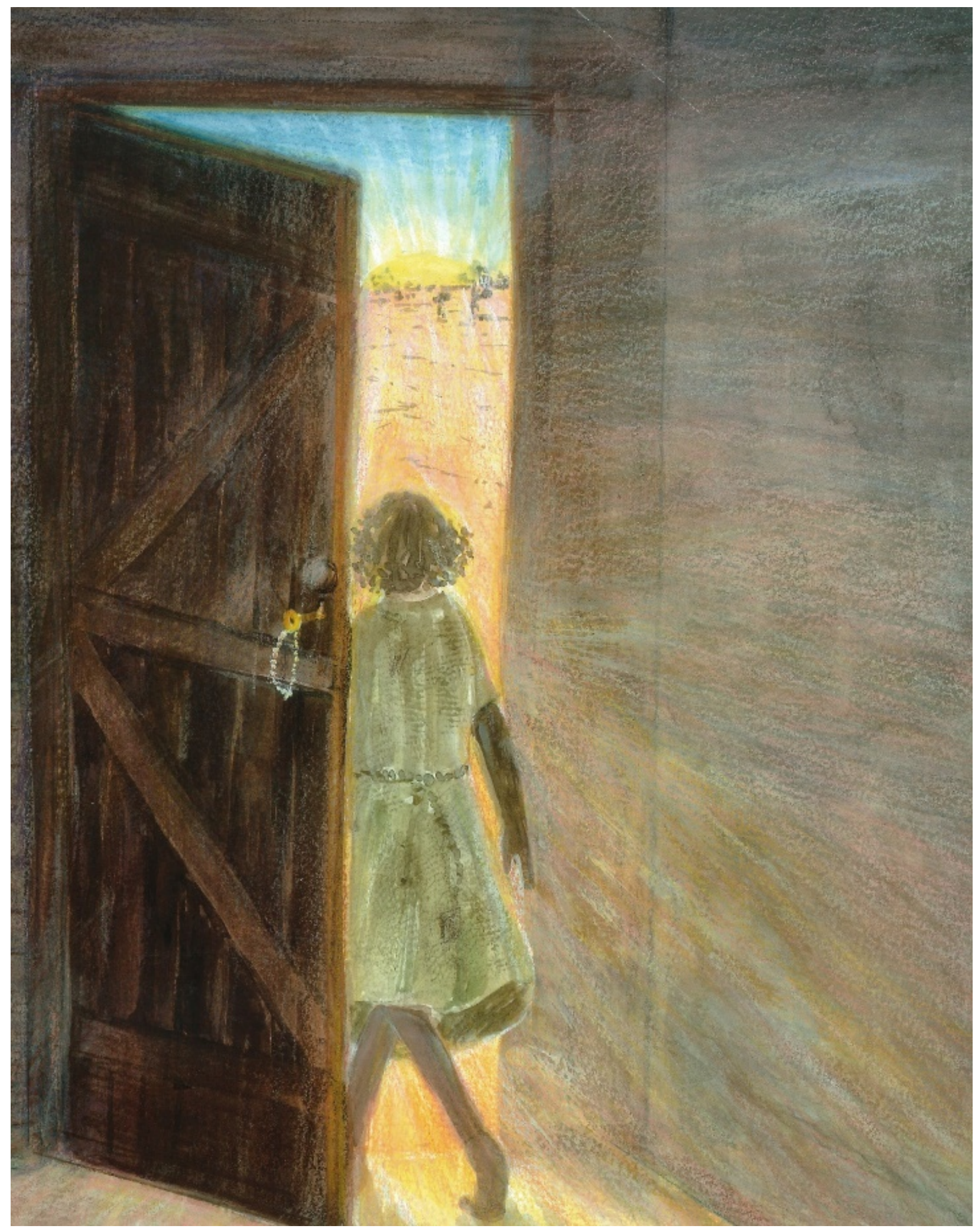

Fig. 20. The girl escapes the children's home: Saffioti, Trina, and Norma MacDonald. Stolen Girl. Magabala Books Aboriginal Corporation, 2011. 


\section{Sorry Day}

Leffler's illustrations combine watercolour, charcoal, and coloured pencil to produce a more realistic rendering of human characters than any other text selected for this study. The content of Sorry Day also varies from the other Canadian and Australian stories examined here because it addresses a recent development in Australia's ongoing process of reconciliation. Nonetheless, this picture book echoes those analysed above in its use of visual and literary techniques intended to establish a juxtaposition between Indigenous and non-Indigenous peoples, places, and cultures. Sorry Day is a fictionalised account of Prime Minister Kevin Rudd's formal apology to the Stolen Generation and their families on behalf of the Australian Government at Parliament House, Canberra on 13 February 2008 (Giannacopoulos 331). The story alternates between the present-day experiences of Maggie and her mother as they listen to the Prime Minister's public address and the past traumas endured by unnamed members of the Stolen Generation as they attempt and ultimately fail to escape from government officials determined to take Aboriginal children to reformative missions. These stories merge in a three-page, fold-out illustration that features prominent colonial figures, like Auber Octavius Neville, Chief Protector of Aboriginals from 1915 to 1936, blending past with present and fact with fiction to stress the historical significance of Maggie's experiences. Sorry Day concludes with photos from Prime Minister Rudd's apology and information about the Stolen Generation, Bringing Them Home, and National Sorry Day.

Sorry Day addresses the Australian federal government's attempts to rectify damages inflicted on Aboriginal children by state missions to educate young audiences about Australia's violent colonial history. Since demands for reparations began in Canada and Australia alike, each government has taken significant strides to provide financial support for the restoration of 
Indigenous cultural practices threatened by colonisation and the redevelopment of Indigenous communities. While the Australian federal government dedicated sixty-three million dollars over four years to victims of the Stolen Generation in response to the 1997 Bringing Them Home report, the Canadian federal government committed 350 million dollars to a "Healing Fund" as part of its Gathering Strength Action Plan in 1998 (Buti). Both the Australian and Canadian federal governments have also formally apologised to the victims of Indigenous missions or residential schools, with Canadian Prime Minister Stephen Harper issuing his apology in June 2008, four months after Prime Minister Rudd (Anderson 572). Sorry Day responds to these reparation efforts by using complimentary textual and visual techniques that suggest Prime Minister Rudd's apology supports vibrant expressions of Indigeneity in a postcolonial society.

Leffler distinguishes between the past and present narratives in Sorry Day using juxtaposing colours that not only celebrate Prime Minister Rudd's apology but also stress the significant role nature plays in supporting Indigenous lifestyles. Leffler's use of bright colours when illustrating images from Maggie's story enables him to convey the joy Maggie and her mother share on the day of Prime Minister Rudd's apology, highlighting how the federal government's willingness to acknowledge Australia's colonial past empowers Aboriginals to embrace their Indigenous identities. The vibrant Aboriginal flags that "flickered in the breeze as Maggie's heart danced with delight" connote Indigenous excitement to finally express the cultural pride previously repressed by colonisation (Vass and Leffler). Leffler's accompanying depiction of Maggie flying her own Aboriginal flag from her mother's shoulders focalises the flag, its bold colours prominent against the soft watercolours of the surrounding image (see fig. 21). By featuring the Aboriginal flag alongside Maggie and her mother's smiling faces, Leffler helps establish a connection between Indigeneity and happy anticipation at the outset of 
Maggie's story. Leffler's vivid present-day illustrations additionally foreground racial diversity amongst those attending Prime Minster Rudd's address, indicating that a vast community recognises the value of Indigeneity and supports Aboriginals in their quest for reparations. This diversity is most prominent in Maggie herself, whose light skin and green eyes differ from her mother's dark complexion and features, positioning Maggie as a mixed-race child — those most actively assimilated into colonial Australian society while government removal of Aboriginal children from their families remained legal (Terszak 100). Maggie's freedom to celebrate Prime Minister Rudd's apology as a mixed-race child suggests that the Australian government's progress towards delivering reparations liberates Aboriginals from oppressive colonial mentalities. While the bright colours Leffler employs to illustrate Maggie's story emphasise Indigenous pride and racial diversity, his monochromatic depictions of the Stolen Generation foreground cultural despair as colonists divide and acculturate Aboriginal communities into Australia's European population.

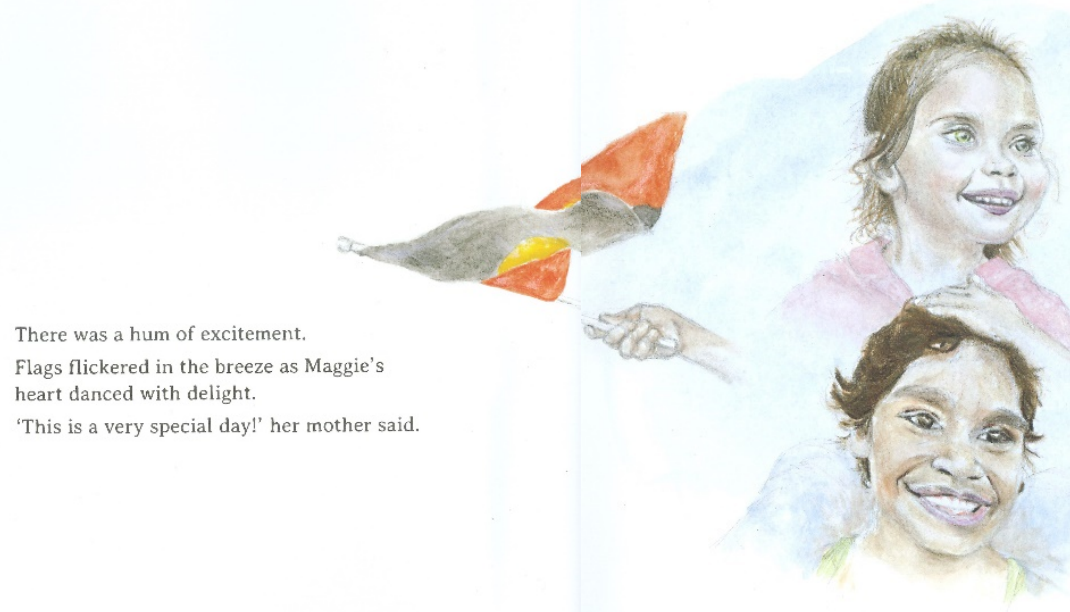

Fig. 21. Maggie waving the Aboriginal flag while sitting on the shoulders of her mother: Vass, Coral, and Dub Leffler. Sorry Day. National Library of Australia, 2018. 
Leffler illustrates the text's narrative about the Stolen Generation in earthy browns that simultaneously establish its temporal distance from Maggie's story and evoke nature to affirm the strength of Indigenous ties to the Australian landscape. When Vass introduces the Aboriginal camp from her narrative about the Stolen Generation, she positions the land as fundamental to Indigenous life: "Long ago and not so long ago, the women sat around the hissing fire. The smell of breakfast flooded the camp as flies circled above. Running in the morning sun, the children kicked up dust" (Vass and Leffler). Nature is intrinsically connected to every activity performed within this Indigenous community, conveying a oneness between Aboriginals and the land that echoes the Australian picture book Stolen Girl (Daozhi 193). Leffler emphasises this unity through brown watercolours that enable his Aboriginal characters to blend into the Australian landscape and images of Aboriginal children "[h]iding in the thick mud," their faces disguised by the long grasses surrounding them (Vass and Leffler, see fig. 22). By overlapping the foliage and the Aboriginal children's faces, Leffler "joins them together into a single unit," further stressing their interdependence (Bang 122). Like the Indigenous peoples in A Coyote Columbus Story, the Aboriginal children in Sorry Day draw on their natural surroundings to evade colonists. However, while Columbus cannot identify Indigenous peoples masquerading as animals, the superior strength and industrial technology that characterise twentieth-century British colonists in Sorry Day enable them to capture and remove Aboriginal children concealed by nature from their homes. Leffler's use of soft browns when depicting Indigenous lifestyles portray Aboriginals in such proximity to the land as to suggest their inseparability, expressing a reciprocal relationship between the Australian landscape and Aboriginal characters in Sorry Day that visually conveys their respect for nature. 


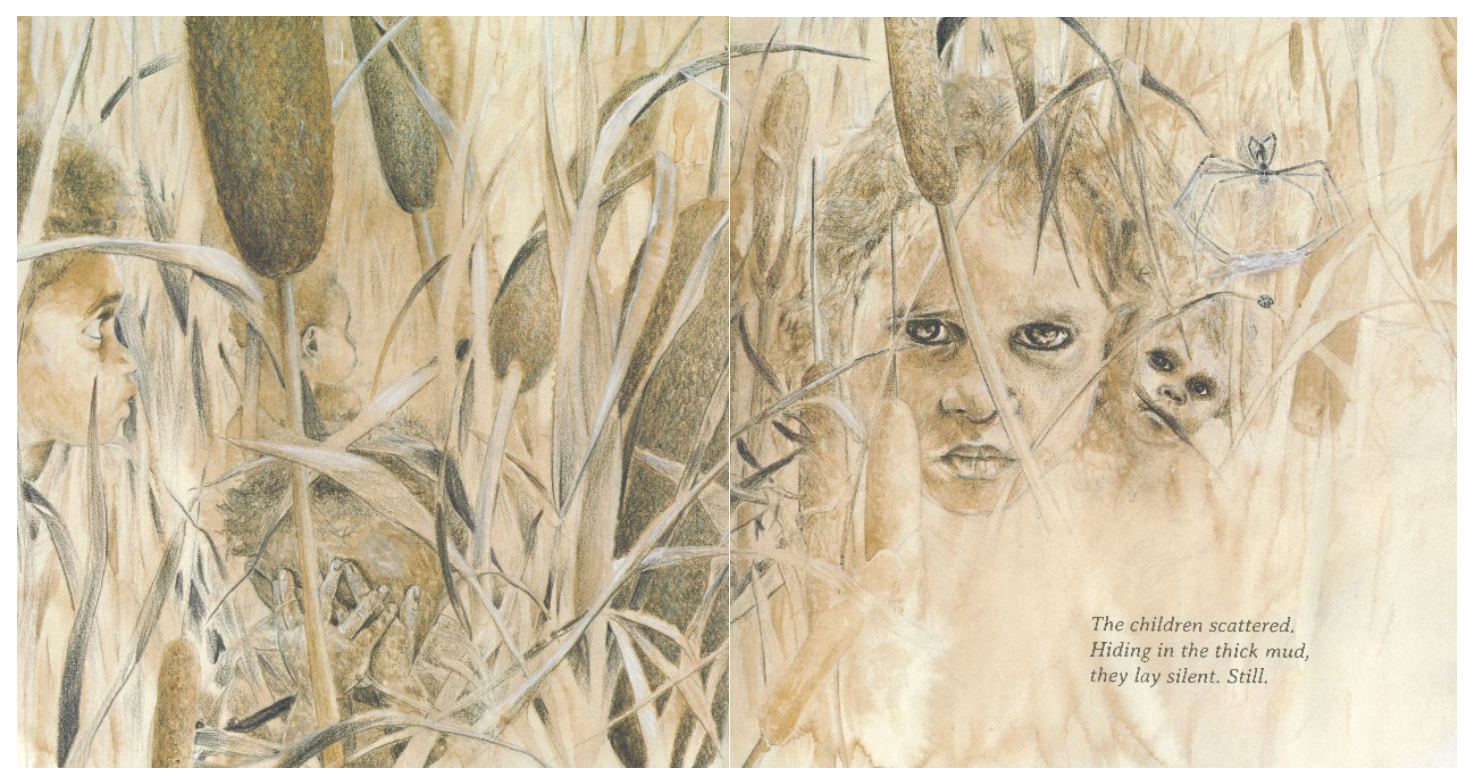

Fig. 22. Aboriginal children hide from colonists in tall grasses: Vass, Coral, and Dub Leffler. Sorry Day. National Library of Australia, 2018.

Vass' narrative about the Stolen Generation contrasts colonial, industrial goods with untainted Australian landscapes, establishing an Indigenous, non-Indigenous juxtaposition that positions colonial forces as technological intruders of Indigenous land. The sound of a truck rumbling "along the bank like thunder" announces the colonists' arrival and suggests that modern technology is synonymous with colonisation in this text (Vass and Leffler). Leffler advances this synecdoche by refraining from illustrating the colonisers' faces and instead depicting only their imposing legs, which he establishes as threatening in the text's previous image of Maggie falling amongst a "sea of legs" (Vass and Leffler). By denying the colonists identities, Leffler allows their technology to denote colonisation. When Vass writes, "The children were found. Screams echoed across the land as they scrambled to escape, sliding in the mud with every step," she portrays the colonisers as an ambiguous but powerful force that renders Aboriginal children helpless in their natural environment (Vass and Leffler). In his accompanying illustration of this scene, Leffler depicts four distinct boot prints encircling a mess 
of slippery footprints, suggesting that modern technology transfers control of nature from Aboriginals to colonists, advantaging them over barefooted Aboriginal children (see fig. 23). These comparatively rigid and smooth shapes further distinguish colonial industry from Indigenous landscapes, enforcing how colonisation impedes on and eventually prevents the persistence of Indigenous relationships with nature. When the colonisers later drive off with Aboriginal children in their truck "leaving behind only billowing dust," their technology further disrupts previously untainted terrain and removes Aboriginal children from every source of cultural pedagogy required to develop their Indigenous identities (Vass and Leffler, Betasamosake Simpson 13). Therefore, similar visual and literary techniques help express how colonial industry triggered the deterioration of land-based Indigenous cultural practices in Sorry Day and The Rabbits, linking these texts despite differences in their narrative content and artistic styles. By opposing invasive colonial technology with open Indigenous landscapes, Vass and Leffler convey how colonisation jeopardises Indigenous connections with nature.

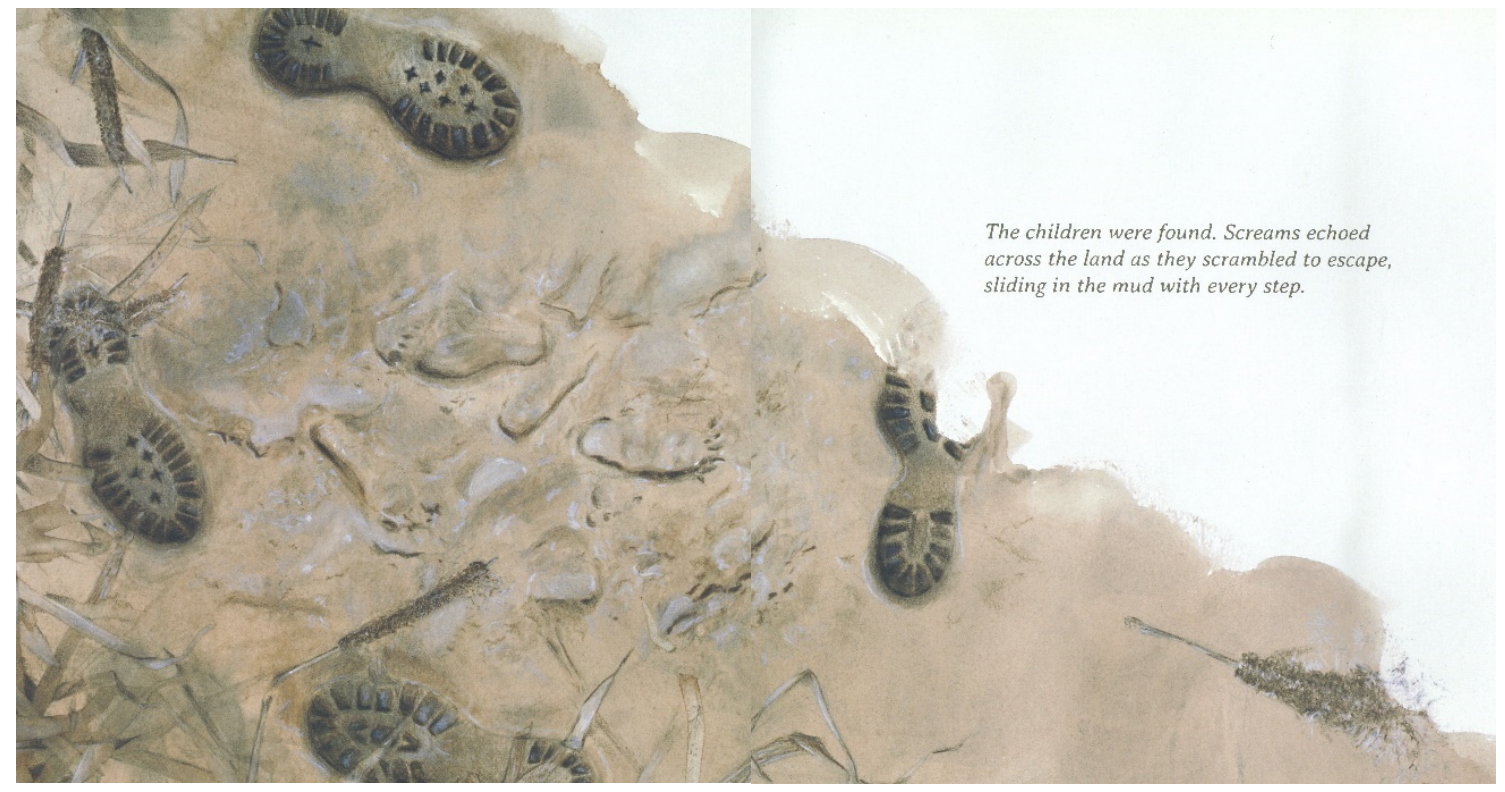

Fig. 23. The boot prints of colonists surrounding the footprints of Aboriginal children: Vass, Coral, and Dub Leffler. Sorry Day. National Library of Australia, 2018. 
The text juxtaposes Maggie's joyful reunion with her mother and the painful separation of Aboriginal children from their mothers to acknowledge how Prime Minister Rudd's formal apology begins repairing the traumas suffered by the Stolen Generation and their families. While the "tender hand" with which Maggie's mother touches her lost daughter conveys gentleness, Vass' use of the word "herded" when describing how colonisers load Aboriginal children "onto the back of the truck" evokes imagery of farmers leading livestock to slaughter, simultaneously indicating that colonisation dehumanises Aboriginals and foreshadowing how colonial missions will attempt to erase their Indigeneity (Vass and Leffler). By contrasting affectionate and abusive physical touch in these two scenes, Vass suggests that Maggie's ability to reconnect with her mother results from decolonisation. Leffler enhances this dichotomy through his opposing illustrations of each passage, blending word and image to position colonisation as the source of separation between Aboriginal children and their families. His depiction of an Aboriginal mother reaching towards the truck containing stolen children as it drives into the distance, a black-clad coloniser leaning off its side, emphasises the vast expanse of earth stretching from the foregrounded mother on the left-hand page to the miniscule, disappearing truck in the upper corner of the right-hand page (see fig. 24). The dusty space dividing mother and truck appears insurmountable, enforcing how colonial missions inflicted irreparable trauma on generations of families that still effects Aboriginals living in Australia today (Walters 127). This image starkly opposes Leffler's colourful illustration of Maggie and her mother smiling radiantly with their faces nuzzled together, which suggests that their proximity and happiness emerges from an absence of colonial threat. Through contrasting colours and shapes, Leffler advances Vass' juxtaposition of Maggie's joyful, modern story with the Stolen Generation's hopeless one, 
ultimately celebrating how Prime Minister Rudd's apology helps repair Indigenous familial relationships damaged by colonisation.
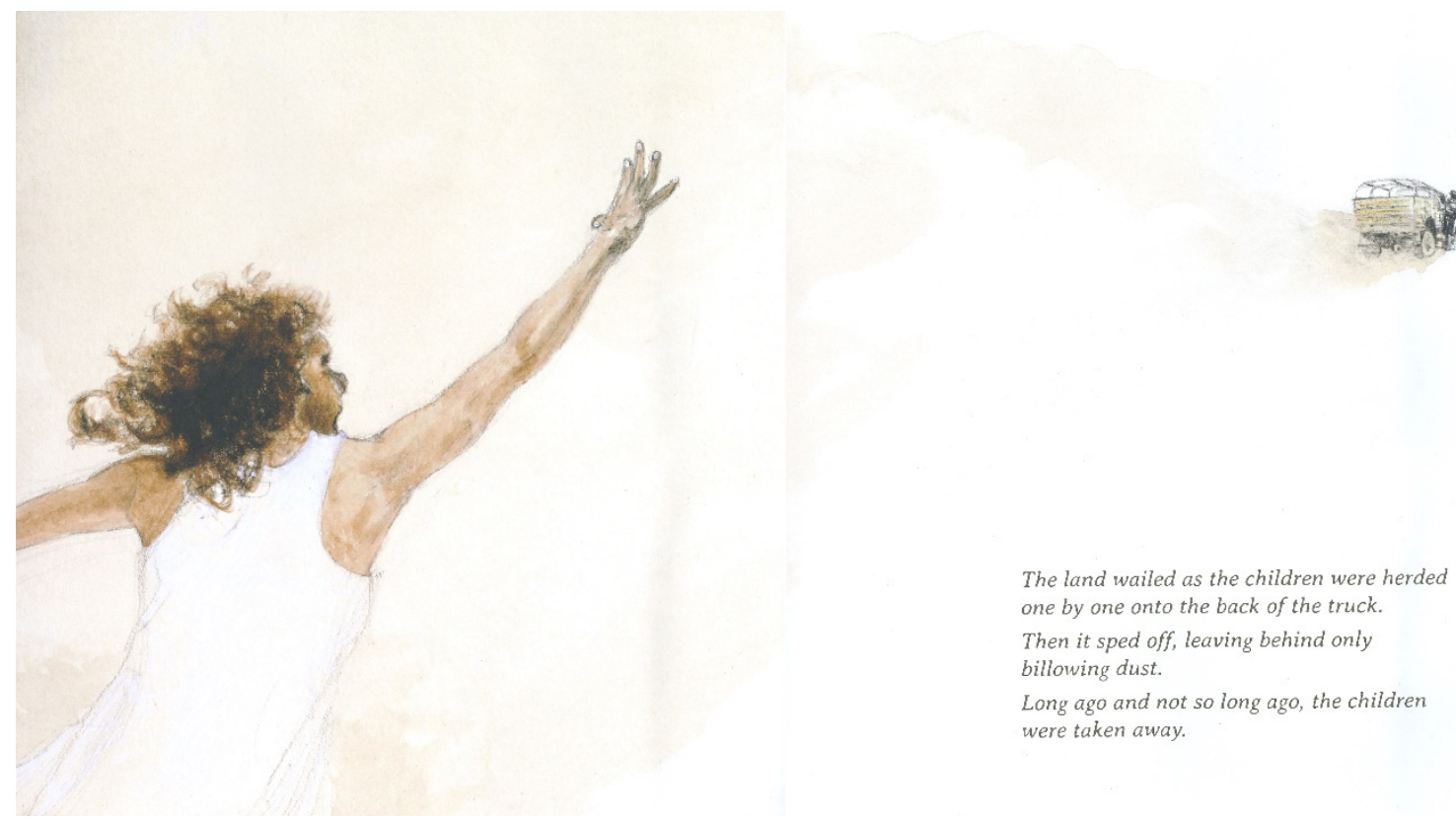

Fig. 24. An Indigenous mother reaches towards stolen Aboriginal children in the colonists' distant truck: Vass, Coral, and Dub Leffler. Sorry Day. National Library of Australia, 2018.

\section{CONCLUSION}

Although the contemporary Canadian and Australian picture books about the European colonisation of Indigenous peoples examined in this paper employ similar techniques for highlighting cultural differences between Indigenous and non-Indigenous peoples and places, their methods for emphasising this dichotomy often vary. While each text visually juxtaposes Aboriginals and colonists using contrasting shapes and colours that ultimately assert the value of Indigenous cultures, these oppositions assume a specific significance within every picture book that collectively reveal thematic differences between Canadian and Australian Indigenous children's literature and, potentially, larger cultural variances amongst Indigenous populations 
within each country respectively. The Australian picture books analysed above more emphatically address how colonisation removes Aboriginals from the land and, thereby, jeopardises their relationships with nature than the Canadian texts. These Australian works textually and visually portray Indigenous landscapes deteriorating following colonial contact, typically because colonists introduce disruptive technology to natural environments, expressing little to no concern for the land intrinsic to Indigenous cultures. While the Canadian picture books certainly express anguish for nature ruined by colonists, these stories focus predominantly on the ways colonial forces aim to destroy Indigenous languages, families, and identities. This effect is achieved through illustrations that grow increasingly monochromatic as colonists remove Indigenous children from homes that encourage their Indigeneity to thrive. Though all three Australian picture books also explore how colonisation threatens Indigenous cultures, they rely primarily on picturesque visual representations of symbiotic Indigenous relationships with nature to convey the value of Indigeneity. I would argue that these textual variations reflect differences within the colonial histories of Canada and Australia, particularly how colonisation impacted and continues to effect Indigenous populations in each country. Additionally, such thematic distinctions highlight the most significant colonial losses suffered by Aboriginals in Canada and Australia respectively, emphasising that reparations are necessary for Indigenous populations to continue generating more positive representations and experiences of Indigeneity.

These texts differ from earlier picture books about Aboriginals because they more explicitly confront colonisation and its lasting impacts on Indigenous communities. While I considered including works that deter from colonial topics in this study, I chose instead to focus on picture books that grapple exclusively with themes of trauma, resistance, and resilience emerging from colonisation. Though many Indigenous artists also produce graphic novels that 
draw on the evocative power of images to make colonisation and its lasting repercussions more accessible for a broad demographic of readers, such as the Canadian anthology This Place: 150 Years Retold (2019) and the Australian anthology Fluid Prejudice (2014), the imposed length of this project prevented me from examining any literary media beyond picture books. However, the volume of dynamic visual texts written and illustrated by Indigenous artists reflects a growing desire for Aboriginals to share their stories and suggests an influx in funding from the federal governments of Canada and Australia alike. While Australia offers its Aboriginal artists significantly less financial support than Canada — a disparity largely resulting from activism for Indigenous peoples by the Truth and Reconciliation Commission of Canada—progress towards delivering reparations in both countries inspires positive cultural change driven by more respectful relationships with Aboriginals (Buti). By othering colonisers through text and images that emphasise the unique vibrancy of Indigenous cultures, these Canadian and Australian picture books ultimately convey that colonisation failed to eradicate Indigeneity. 


\section{WORKS CITED}

Allan, Cherie. "Introduction: Looking Back.” Playing with Picturebooks: Postmodernism and the Postmodernesque, Palgrave Macmillan, 2012, pp. 1-26.

Anderson, Willow J. “'Indian Drum in the House': A Critical Discourse Analysis of an Apology for Canadian Residential Schools and the Public's Response.” The International Communication Gazette, vol. 74, no. 6, 2012, pp. 571-585.

Bang, Molly. Picture This: Perception and Composition. Bulfinch Press, 1991.

Barnes, Rosemary, and Nina Josefowitz. "Indian Residential Schools in Canada: Persistent Impacts on Aboriginal Students' Psychological Development and Functioning." Canadian Psychological Association, vol. 60, no. 2, 2019, pp. 65-76.

Betasamosake Simpson, Leanne. "Land as Pedagogy: Nishnaabeg Intelligence and Rebellious Transformation.” Decolonization: Indigeneity, Education \& Society, vol. 3, no. 3, 2014, pp. 1-25.

Beveridge, Lorraine, and Julie Hinde McLeod. “Action Learning through Indigenous Literature.” Intercultural Education, vol. 20, no. 2, 2009, pp. 187-197.

“Biography.” Kent Monkman, www.kentmonkman.com/biography. Accessed 8 July 2019.

Bird Rose, Deborah. Nourishing Terrains: Australian Aboriginal Views of Landscape and Wilderness. Australian Heritage Commission, 1996.

Bombay, Amy, Kimberly Matheson, and Hymie Anisman. "The Intergenerational Effects of Indian Residential Schools: Implications for the Concept of Historical Trauma." Transcultural Psychiatry, vol. 51, no. 3, 2014, pp. 320-338.

Bradford, Clare. "Introduction." Unsettling Narratives: Postcolonial Readings of Children's Literature, Wilfrid Laurier University Press, 2007, pp. 1-16. 
Buckner, Phillip. "The Consolidation of British North America, 1783-1860." Canada and the British Empire, Oxford Scholarship Online, 2010, pp. 42-72.

Buti, Antonio. "The Removal of Aboriginal Children: Canada and Australia Compared." University of Western Sydney Law Review, vol. 6, no. 1, 2002.

Cahill, Donald, and Martin Ouellet. “An Analysis of Jacques Cartier's Exploration of the Gaspé Coast, 1534." Acadiensis: Journal of the History of the Atlantic Region, vol. 44, no. 2 , 2015, pp. 75-94.

Clarke, Frank G. "European Arrivals and Colonization (Seventeenth Century-1830)." History of Australia, Greenwood Publishing Group, 2002, pp. 21-39.

Conrad, Margaret. "Natives and Newcomers, 1000-1661." A Concise History of Canada, Cambridge University Press, 2012, pp. 26-50.

Creighton, Donald. "The Economy of the North." The Empire of the St. Lawrence: A Study in Commerce and Politics, University of Toronto Press, 1956, pp. 1-21.

Daozhi, Xu. "Australian Children's Literature and Postcolonialism: A Review Essay.” Ilha do Desterro, vol. 69, no. 2, 2016, pp. 193-205.

Edwards, Gail, and Judith Saltman. "Canadian Cultural Identity, Canadian Cultural Identities." Picturing Canada: A History of Canadian Children's Illustrated Books and Publishing, University of Toronto Press, 2010, pp. 191-226.

Florence, Melanie, and Gabrielle Grimard. Stolen Words. Second Story Press, 2018.

Giannacopoulos, Maria. “The Nomos of Apologia.” Griffith Law Review, vol. 18, no. 2, 2009, pp. 331-349.

Graham, Judith. Pictures on the Page. Australian Reading Association, 1990. 
Iannella, Amy, David Peacock, Phillip Cassey, and Nina Schwensow. "Genetic Perspectives on the Historical Introduction of the European Rabbit (Oryctolagus Cuniculus) to Australia." Biol Invasions, vol. 21, no. 1, 2019, pp. 603-614.

Jordan-Fenton, Christy, Margaret Pokiak-Fenton, and Gabrielle Grimard. When I Was Eight. Annick Press, 2013.

King, Thomas, and William Kent Monkman. A Coyote Columbus Story. House of Anansi Press, 1992.

Konishi, Shino, and Maria Nugent. "Newcomers, c. 1600-1800." The Cambridge History of Australia, Cambridge University Press, edited by Alison Bashford and Stuart Macintyre, 2013, pp. 43-67.

Lucie \& Nkechi. "Shaun Tan: Straight Talking Dreamer." The Pin: Race, Identity, Culture, 10 February 2018, www.thepin.org/meet/shaun-tan. Accessed 2 July 2019.

Lyon, David. Postmodernity. $2^{\text {nd }}$ ed., Open University Press, 1999.

Marsden, John, and Shaun Tan. The Rabbits. Hachette Australia, 1998.

Matheson, Kimberly, Amy Bombay, Kaylyn Dixon, and Hymie. "Intergenerational Communication Regarding Indian Residential Schools: Implications for Cultural Identity, Perceived Discrimination, and Depressive Symptoms.” Transcultural Psychiatry, 2019, pp. $1-28$.

McGlasson, Dianne. “A Toothy Tale: Themes of Abjection in John Marsden and Shaun Tan's Picture Story Book, The Rabbits." The Lion and the Unicorn, vol. 37, no. 1, 2013, pp. $20-36$.

Moberg, Mark. Engaging Anthropological Theory: A Social and Political History. Routledge, 2013. 
Nabizadeh, Golnar. “Of Rabbits and Pirates: After-Images of E. Philips Fox's 'Landing of Captain Cook at Botany Bay, 1770.’” Adaptation, vol. 9, no. 1, 2015, pp. 35-45.

Nodelman, Perry. “The Other: Orientalism, Colonialism, and Children's Literature.” Children's Literature Association Quarterly, vol. 17, no. 1, 1992, pp. 29-35.

"Preferences in Terminology when Referring to Aboriginal and/or Torres Strait Islander Peoples." Gulanga Program, Dec. 2016, www.actcoss.org.au/sites/default/files/public/publications/gulanga-good-practice-guidepreferences-terminology-referring-to-aboriginal-torres-strait-islander-peoples.pdf. Accessed 8 August 2019.

Rifkin, Mark. "Indigenous Orientations." Beyond Settler Time: Temporal Sovereignty and Indigenous Self-Determination, Duke University Press, 2017, pp. 1-47.

Rivkin, Julie, and Michael Ryan. "Ethnic, Indigenous, Post-Colonial, and Transnational Studies." Literary Theory: An Anthology. $3^{\text {rd }}$ ed., John Wiley \& Sons, 2017, pp. 10991251.

Saffioti, Trina, and Norma MacDonald. Stolen Girl. Magabala Books Aboriginal Corporation, 2011.

Said, Edward. Orientalism. Pantheon, 1978.

See, Scott W. "Native Peoples, Europeans, and a Clash of Cultures (Prehistory-1663)." The History of Canada, Grey House Publishing. $2^{\text {nd }}$ ed., 2010.

Sipe, Lawrence R. "How Picture Books Work: A Semiotically Framed Theory of Text-Picture Relationships." Children's Literature in Education, vol. 29, no. 2, 1998, pp. 97-108.

Stephens, John, Ken Watson, and Judith Parker. From Picture Book to Literary Theory. St Clair Press, 2003. 
“Terminology.” Indigenous Foundations, 2009, www.indigenousfoundations.arts.ubc.ca/terminology/. Accessed 8 August 2019. Terszak, Mary. "Literature Review: Setting the Stage for Understanding." Orphaned by the Colour of My Skin: A Stolen Generation Story, Routledge, 2007, pp. 95-114.

“Thomas King.” Penguin Random House Canada, 2019, www.penguinrandomhouse.ca/authors/15740/thomas-king. Accessed 8 July 2019.

Vass, Coral, and Dub Leffler. Sorry Day. National Library of Australia, 2018.

Walters, Janice A. "Trauma and Resilience among a Stolen Generation of Indigenous People." Fragments of Trauma and the Social Production of Suffering: Trauma, History, and Memory, edited by Michael O'Loughlin and Marilyn Charles, Rowman \& Littlefield Publishers, 2014, pp. 127-148.

West, Barbara. “Aboriginal History.” A Brief History of Australia, Facts on File, 2010, pp. 1330.

West, Barbara. "European Exploration and Early Settlement." A Brief History of Australia, Facts on File, 2010, pp. 31-57.

Wolf, Doris, and Paul De Pasquale. "Home and Native Land: A Study of Canadian Aboriginal Picture Books by Aboriginal Authors." Discourses of Children's Literature in Canada, Wilfred Laurier University Press, 2008, pp. 87-105.

Wu, Shuxuan. "A Multimodal Analysis of Image-text Relations in Picture Books." Theory and Practice in Language Studies, vol. 4, no. 7, 2014, pp. 1415-1420. 